\title{
ANTONIO DE CAPMANY Y LA CIUDAD DE BARCELONA: EL VALOR DE LO EMPÍRICO EN LA SENDA DEL PROGRESO
}

\author{
Antonio de Capmany and the city of Barcelona: \\ the value of experience in the path of progress
}

\author{
Ramon GRAU I FERNÁNDEZ \\ Archivo Histórico de la Ciudad de Barcelona \\ ramongrauf@gmail.com
}

Fecha de recepción: 10/01/2016

Fecha de aceptación definitiva: 12/05/2016

RESUMEN: En su tiempo, Antonio de Capmany (1742-1813) fue el intelectual más destacado al servicio de los intereses de Barcelona, dentro de una voluntad por articular la evidente energía de esa ciudad con los esfuerzos desplegados por el despotismo ilustrado para relanzar a España como una potencia continental y colonial. Un amplio conocimiento y asimilación de la cultura europea de la Ilustración le permitieron asociar la experiencia histórica de la capital de Cataluña con los valores modernos. No se trató de un simple barniz, puesto que esa apología de Barcelona como foco de progreso se construyó a partir de datos empíricos documentados y de impresiones sensoriales, de acuerdo con los principios predicados por los grandes filósofos británicos frente al racionalismo especulativo y a sus ocurrencias incesantes.

Palabras clave: Antonio de Capmany; Barcelona; empirismo; progreso; gremios; arquitectura gótica.

ABSTRACT: In his time, Antonio de Capmany (1742-1813) was the most prominent intellectual in the service of the interests of Barcelona, in a willingness to articulate the energy of that city with the efforts of enlightened despotism to relaunch 
Spain as a continental and colonial power. Extensive knowledge and assimilation of European culture of the Enlightenment allowed him to associate the historical experience of the Catalan capital with modern values. It was not a simple varnish, since the defense of Barcelona as the focus of progress was constructed from documented empirical data and sensory impressions, according to the principles preached by the great British philosophers against speculative rationalism and its incessant occurrences.

Key words: Antonio de Capmany; Barcelona; empiricism; progress; guilds; gotic architecture.

Al iniciarse el siglo XVIII, Barcelona se hizo célebre, primero como efímera Corte de Carlos III de Habsburgo y, poco después, como principal y casi último punto de resistencia frente a Felipe $\mathrm{V}$ de Borbón, que se posesionó de ella en septiembre de 1714 tras un largo asedio. Al acabar la centuria, a pesar de que la Revolución francesa había inaugurado otra etapa turbulenta en Europa, que afectó directamente a la ciudad, la fama de Barcelona poco tenía que ver con el estrépito de las armas; descansaba en un espectacular desarrollo económico que la hacía despuntar entre las ciudades españolas e incluso figurar como una de las principales urbes industriales del continente.

En los cuarenta años comprendidos entre el inicio de su carrera como escritor en 1773 y su fallecimiento siendo diputado en las Cortes de Cádiz, Antonio de Capmany y de Montpalau (1742-1813), heredero de una familia de caballeros que había optado por el partido austriacista en la Guerra de Sucesión, fue el intelectual más destacado al servicio de los intereses de Barcelona -y por extensión de Cataluña- dentro de una voluntad de articular esa energía local con los esfuerzos desplegados en España para relanzarla como gran potencia continental y colonial bajo los gobiernos del despotismo ilustrado de Carlos III de Borbón y, a partir del impacto de la Revolución francesa, en un contexto de lucha por la supervivencia nacional.

El valor duradero de sus aportaciones a propósito de Barcelona descansa, por un lado, en la aplicación de los métodos de crítica documental y bibliográfica, puestos a punto por diversas comunidades eclesiásticas para depurar la maltratada historia medieval, y, por el otro, en un amplio conocimiento y asimilación de la cultura europea de la Ilustración, que le permitió releer el bagaje histórico de la capital de Cataluña dándole un incuestionable aire de modernidad.

Dentro de la amalgama de teorías filtradas por la célebre Encyclopédie, el pensador catalán se mostró escéptico ante las aportaciones del racionalismo especulativo, fuente de las incesantes ocurrencias de los ministros ilustrados, y eligió como brújula segura el criterio de sujeción a los datos empíricos, derivados, a la postre, de impresiones sensoriales. En una etapa cultural de fuerte influencia francesa en España, la aproximación de Capmany al pasado destaca, gracias a esa apertura sistemática a las doctrinas del empirismo británico, por una capacidad 
singular de comprensión del legado histórico, que se manifiesta con especial fuerza, por ejemplo, en la evaluación positiva de la herencia urbanística y arquitectónica de Barcelona. Sus proyecciones sociales y políticas hacia el futuro, por otro lado, se mantuvieron siempre profundamente enraizadas en esa misma historia, incluso -o sobre todo- cuando la invasión napoleónica y el colapso de la dinastía borbónica obligaron a intentar la refundación del Estado sobre bases más seguras y competitivas.

\section{DOS AFIRMACIONES EMPÍRICAS INICIALES}

En 1773 Antonio de Capmany había abandonado su primera profesión, el ejercicio de las armas, y empezaba a construirse otra imagen pública como hombre de letras. Esta nueva personificación descansó inicialmente en el estudio comparado de las lenguas castellana y francesa y en la actualización de la retórica española, con una primera culminación en la Filosofía de la eloqüencia de 1777, obra que sigue muy de cerca doctrinas divulgadas por la Encyclopédie de Diderot y D'Alembert ${ }^{1}$. Capmany seguiría cultivando con interés y rendimiento notable esta vertiente filológica, que indudablemente guarda relación con los esfuerzos regeneracionistas desplegados por el despotismo ilustrado español a través de sus academias. No obstante, con alcance político y social más directo elaboró en la misma década de 1770 sendas respuestas críticas a dos personajes destacados de su tiempo: el notable ensayista y creador literario José Cadalso y el entonces todopoderoso ministro José Rodríguez Campomanes. En ellas afloran el sustrato teórico y algunas de las tesis que Capmany desarrollaría en clave historiográfica entre 1779 y 1807 y en clave estrictamente política a partir de $1808^{2}$.

1. ÉTIENVRE, Françoise. Rhétorique et patrie dans l'Espagne des Lumières. L'oeuvre linguistique d'Antonio de Capmany (1742-1813). Paris: Honoré Champion, 2001, pp. 130-135; Berbel RodríguEZ, José Juan. "Introducción». En CAPMANY y MONTPALAu, Antonio de. Filosofía de la elocuencia (1777). Almería: Universidad de Almería, 2002, pp. 7-25.

2. Esta última etapa vital, que queda al margen de nuestro análisis, ha sido muy bien documentada por Fernández de la Cigoña, Francisco José y CANTERo, Estanislao. Antonio de Capmany (17421813). Pensamiento, obra bistórica, política y jurídica. Madrid: Fundación Francisco Elías de Tejada y Erasmo Percopo, 1993. Son importantes para la materia los estudios de los hispanistas Pierre Vilar y Françoise Étienvre: VILAR, Pierre. Assaigs sobre la Catalunya del segle XVIII. Barcelona: Curial, 1973, pp. 91-171. ÉTIENVRE, Françoise. «Introducción biográfica y crítica». En CAPMANY, Antonio de. Centinela contra franceses. Londres: Tamesis Books, 1988, pp. 13-72. De la misma autora: «Nación y constitución en Antonio de Capmany». En CANTERla González, Cinta (coord.). Nación y constitución: de la Ilustración al liberalismo. Sevilla: Junta de Andalucía, 2006, pp. 265-275. También puede leerse: GRAU, Ramon. "Pierre Vilar, Antoni de Capmany i la "gimnàstica mental". En El (re)descobriment de l'Edat Moderna. Estudis en homenatge a Eulàlia Duran. Barcelona: Publicacions de l'Abadia de Montserrat, 2007, pp. 199-217. 


\subsection{El progreso en la Europa moderna y el atraso español}

Poco después del final de la Guerra de Sucesión a la Corona Hispánica, Montesquieu había escrito las famosas Lettres Persanes, donde las impresiones de viaje de unos supuestos observadores orientales servían para satirizar las costumbres europeas y, en particular, las francesas. En ese desenfadado contexto, una de las cartas ofrece como contrapunto las impresiones de un imaginario viajero francés sobre la sociedad española. Tal vez porque en 1748 la sustancia de esas críticas a España había reaparecido en las serias páginas de L'Esprit des lois, José Cadalso creyó oportuno todavía en 1772 impugnar punto por punto, dentro de Los Eruditos a la violeta, los juicios variopintos que el célebre teórico de la división de poderes había puesto en boca de un personaje de ficción y referibles, en cualquier caso, a un tiempo pretérito, la España de los últimos Austrias.

El primer escrito conocido de Antonio de Capmany, firmando como «Pedro Fernández", es precisamente su respuesta a Cadalso, encabezada por una frase enigmática: "Hoy tomo la pluma sin saber por qué, tanto es verdad que nosotros mismos ignoramos muchas veces el verdadero móvil de nuestras acciones $»^{3}$. Para el descubridor moderno del manuscrito, Julián Marías, que no pudo en 1963 averiguar quién se ocultaba tras el seudónimo, no se trataba, ni mucho menos, de una obra circunstancial y sin rumbo preciso, como sugiere aquel tono desganado, que iba a consolidarse como uno de los recursos retóricos favoritos del Capmany polemista. Al contrario, consideró que "nadie había tenido en su tiempo una visión más amplia, profunda y justa del problema»; el "problema» por excelencia de España: cómo hacer compatible la continuidad nacional con la adhesión práctica a los logros obtenidos en la Europa moderna. Por ello, el fiel discípulo de Ortega y Gasset convirtió el escrito de Capmany en fuente de inspiración para una especulación intelectual melancólica sobre "la España posible en tiempo de Carlos III", anterior a la tendencia fratricida que habría de dominar el país a partir del estallido de la Revolución francesa y hasta la larga posguerra de $1939^{4}$.

$\mathrm{Al}$ conceder que una gran parte de las observaciones críticas de Montesquieu era acertada, el Comentario sobre el Doctor Festivo se presenta, de hecho, como la aplicación al caso de España de los resultados de la célebre polémica de los Antiguos y los Modernos, que había quedado zanjada en Francia tiempo atrás a favor de la superioridad de la nueva cultura científica. Para Capmany era tan evidente "la ventaja de este siglo sobre los precedentes en el uso de la razón humana» como que "nosotros [los españoles] somos de los que menos hemos contribuido para hacer la Europa moderna, tan superior a la antigua»; aunque, por fortuna, «la gloria

3. [CApmany y de Montpalau, Antonio de] "Pedro Fernández". Comentario sobre el Doctor Festivo y Maestro de los Eruditos a la violeta, para desengaño de los españoles que leen poco y malo (Sevilla, 28 de enero de 1773). En MaríAs, Julián. La España posible en tiempo de Carlos III. Madrid: Sociedad de Estudios y Publicaciones, 1963, pp. 181-218. La cita en pp. 183-184.

4. MARÍAs. La España posible..., p. 219. 
de este todo cubre a todas sus partes», incluida España si optare por sumarse a la corriente general5.

Conocedor ya de la autoría del Comentario sobre el Doctor Festivo, Hans Juretschke pudo relacionar en 1969 el escrito con la circunstancia vital de Antonio de Capmany en aquel año de 1773. Sin negar «que la exposición fuera intencionalmente sincera y objetiva", pensó que su finalidad concreta sería "ofrecerse como colaborador del equipo carolino" y "granjearse el favor de Olavide», de quien, en efecto, "obtuvo poco después el encargo de traer colonos catalanes a Sierra Morena" ${ }^{6}$. La hipótesis otorga centralidad a una parte del Comentario menos llamativa que la puntual enumeración de los grandes sabios de la Europa contemporánea y donde, siguiendo el guion de las Lettres persanes, se abordan los mitos sobre la prosperidad material de España en el pasado.

De acuerdo con los viejos tópicos sobre la Antigüedad clásica, Cadalso había estimado la población de la península Ibérica en cincuenta millones de personas para la época de Augusto, de manera que los nueve de su tiempo le parecerían un signo inequívoco de decadencia. Eso le llevaba a subrayar como paliativos, frente a la tétrica pintura trazada por Montesquieu, los frutos del esfuerzo del trabajo agrícola en Cataluña y la fertilidad de Andalucía, Murcia y Castilla la Vieja. El comentarista barcelonés aprovecha esas alegaciones de Cadalso para disociar los casos de Cataluña y del resto de España, lo cual da una clave para comprender esa excepcional sintonía con el espíritu europeo que tanto admiraba a Julián Marías. Admitiendo -claro está- el mérito catalán, Capmany subraya la paradoja de que precisamente "la pródiga y espontánea fructificación de la Naturaleza» en esas otras provincias es la que en ellas «ha hecho perder el amor al trabajo y a la industria" ${ }^{7}$.

La evidencia de la moderna expansión demográfica catalana, sobre un territorio proverbialmente pobre en comparación con otras regiones, fue, sin duda, un acicate para aplicar al caso español el pasaje de L'Esprit des lois en donde Montesquieu, además de establecer una relación no lineal entre calidad del suelo y cuantía de la población, pone el acento en la eficacia del principio de la libertad civil como verdadera raíz de la actividad económica y de la riqueza colectiva:

Les pays ne sont pas cultivés en raison de leur fertilité, mais en raison de leur liberté; et si l'on divise la terre par la pensée, on sera étonné de voir la plupart du temps des déserts dans ses parties les plus fertiles, et de grands peuples dans celles où le terrain semble refuser tout ${ }^{8}$.

5. Capmany. Comentario sobre el Doctor Festivo..., pp. 201-202.

6. JuRETSChKe, Hans. "La contestación de Capmany a Cadalso y su discurso de ingreso en la Academia de la Historia». Revista de la Universidad de Madrid, 1969, XVIII, 69, p. 214.

7. CAPMANY. Comentario sobre el Doctor Festivo..., p. 211.

8. Montesquieu, Charles-Louis Sécondat, barón de. L'Esprit des lois (1748). En Oeuvres complètes. Paris: Éditions du Seuil, 1964, p. 633. 
El joven Capmany no asume aún el riesgo de alegar el concepto de libertad, especialmente espinoso en la España sometida a los tribunales inquisitoriales, sino que se sitúa en un territorio puramente utilitario, acercándose a Denis Diderot, otra referencia importante, aunque también imposible de explicitar. Acordándose al parecer de una célebre máxima poblacionista de Jean Bodin, «il n’y a richesse ny force que d'hommes", e inspirado probablemente por las nuevas doctrinas fisiocráticas, en su artículo "Homme», publicado en 1765, el enciclopedista había equiparado la tierra y el hombre como fuentes de la riqueza del Estado:

Il n'y a de véritables richesses que l'homme et la terre. L'homme ne vaut rien sans la terre, et la terre ne vaut rien sans l'homme. L'homme vaut par le nombre; plus une société est nombreuse, plus elle est puissante pendant la paix, plus elle est redoutable dans les tems de la guerre. Un souverain s'occupéra donc sérieusement de ses sujets?

Con la Cataluña renaciente a la vista, nuestro autor desequilibra de nuevo la balanza en favor del factor humano, sin olvidar los beneficios que revierten en la propia clase trabajadora, aunque adopte formalmente el punto de vista de los intereses prácticos de la monarquía y lo remache con una alabanza superlativa de Carlos III. En efecto, a diferencia de sus predecesores de los siglos XVI y XVII, se supone que este rey ilustrado no se ufanaría ya de la mera extensión de sus dominios, puesto que

... sus benéficos cuidados y paternal celo no conspiran sino al aumento de los hombres y a la cultivación de la tierra: dos cosas que constituyen la fuerza real y constante de un soberano. La tierra, por sí, no tiene valor real, sino el que le quiere dar la mano gloriosa del hombre. [...] El trabajo, sólo, produce hombres y los deja en la mediocridad dorada, porque hace a todos igualmente ricos ${ }^{10}$.

En este contexto, Capmany puede explotar sin ambages la fama de la laboriosidad catalana para sus proyectos regeneradores en emulación de Europa. En la repoblación de Sierra Morena, pretenderá exhibir ante Olavide -probablemente con ingenuidad excesiva- la excepcional utilidad de la contribución catalana al engrandecimiento de España y de la Corona.

\subsection{El valor de la organización corporativa del trabajo}

Mientras Capmany ponía el punto final a su Comentario sobre el Doctor Festivo en Sevilla y se aprestaba a conducir a un grupo de catalanes hasta La

9. Diderot, Denis. «Homme». En Encyclopédie ou Dictionnaire raisonné des sciences, des arts et des métiers. Paris, 1765, vol. 8, p. 278. El antecedente: BoDin, Jean. Les six livres de la République. Paris, $1578,3 .^{\mathrm{a}}$ ed., p. 518.

10. Capmany. Comentario sobre el Doctor Festivo..., p. 209. 
Carolina, en Barcelona se gestaba una insurrección contra el designio real de establecer en el Principado el servicio militar obligatorio mediante el sorteo de quintas, que estalló como motín el día 4 de mayo de 1773 y tuvo efectos duraderos en forma de resistencia civil, organizada por los colegios y gremios de la ciudad y amparada por autoridades locales, tanto del ámbito eclesiástico como del civil. En otoño de 1774, cuando la diputación catalana emanada de la reunión de las corporaciones barcelonesas apenas había dejado de ejercer su poder al margen de la legalidad monárquica, Pedro Rodríguez Campomanes, fiscal del Consejo de Castilla, daba a la imprenta el célebre Discurso sobre el fomento de la industria popular, donde proponía la desurbanización de las actividades industriales, "porque el verdadero interés del Estado consiste en mantener dispersa la industria en caserías y lugares chicos ${ }^{11}$. Es difícil no percibir un eco de la insurrección barcelonesa en la explícita articulación de esta consigna política con la reconocida peculiaridad del carácter catalán, paradójica combinación a los ojos del ministro:

Una de las causas principales del fomento de las artes en Cataluña consiste en que los oficios se miran en el pueblo con el mismo honor que la labranza y es muy del caso esta opinión razonable para sostener la industria popular [...]. Pero hay la muy perjudicial práctica de haber reducido en Cataluña a gremios exclusivos a los artesanos, cuyos gremios sólo subsisten en las ciudades populosas del Principado y causan un verdadero estanco de la industria en perjuicio de las otras poblaciones. Tales gremios tienen directa oposición a la felicidad pública y apartan de las aldeas y villas la propagación de la industria ${ }^{12}$.

La ofensiva de Campomanes se producía, desde luego, a la vista del ambiente político creado en Francia por las doctrinas fisiocráticas, divulgadas por la Encyclopédie y que iban a culminar -efímeramente- en los decretos abolicionistas preparados por Turgot y suscritos por Luis XVI en marzo de $1776^{13}$.

En defensa de la compleja economía urbana, aunque sin referirse apenas al caso barcelonés, Capmany publicó en 1778, bajo el seudónimo "Ramón Miguel Palacio» y una dedicatoria al mismo Campomanes, un Discurso económico-político

11. [CAmpomanes, Pedro Rodríguez]. Discurso sobre el fomento de la industria popular. Madrid: Antonio de Sancha, 1774 , p. LXXIII.

12. CAMPomanes. Discurso sobre el fomento..., p. LXVIII, nota 15. Sobre el desarrollo del motín de 1773 remitimos a GRAu i FERnÁndez, Ramon. Antoni de Capmany i la renovació de l'bistoricisme polític català. Barcelona: Ajuntament de Barcelona (Quaderns del Seminari d'Història de Barcelona, 8), 2006, pp. 27-37; y para la génesis del Discurso sobre el fomento de la industria popular, a GRAU I FERNÁNDEZ, Ramon. "Indústria urbana o indústria dispersa? El rerefons polític d'una polèmica, 17731778». En SÁNCHEZ, Àlex (coord.). La indústria de les indianes a Barcelona, 1730-1850. Barcelona: Ajuntament de Barcelona (Barcelona Quaderns d'Història, 17), 2011, pp. 149-195.

13. [ClicQuot de BleRvache, Simon]. Considérations sur le commerce, et en particulier sur les compagnies, sociétés et maîtrises. Ámsterdam, 1758. Procès-verbal de ce qui s'est passé au lit de justice tenu par le roi à Versailles, le mardi douze mars 1776. Paris: Imprimerie Royale, 1776. 
en defensa del trabajo mecánico de los menestrales y de la influencia de sus gremios en las costumbres populares, conservación de las artes y honor de los artesanos $^{14}$. En 1788, el Semanario erudito editado por Antonio Valladares de Sotomayor publicó como obra de autor desconocido un Discurso político-económico sobre la influencia de los gremios en el Estado, en las costumbres populares, en las artes $y$ en los mismos artesanos ${ }^{15}$. Su descubridor moderno, Luis Sánchez Agesta, no tuvo grandes dificultades para establecer que se trataba de otra versión del texto publicado en 1778, que su autor no podía ser otro que el mismo Capmany y, más aún, que se trataba de la forma original y más dura de su crítica a las propuestas politicoeconómicas de Campomanes, antes de que éste moderase su actitud en el Discurso sobre la educación popular de los artesanos y su fomento de $1775^{16}$.

La devaluación de las especulaciones típicas del despotismo ilustrado a la vista de la realidad empírica, "los hechos", es el eje del argumento de Capmany:

Este problema político de la necesidad de los gremios para la conservación, honor y enseñanza de las artes tiene todos los hechos a favor de ellos, y sólo las especulaciones en contra; porque en esta materia, en que la eloqüencia nada prueba, la experiencia lo explica todo. Los efectos de la industria asociada los hemos visto, y los de las artes errantes y desunidas están por ver ${ }^{17}$.

14. [CApmany y de Montpalau, Antonio de] "Ramon Miguel Palacio». Discurso económicopolítico en defensa del trabajo mecánico de los menestrales y de la influencia de sus gremios en las costumbres populares, conservación de las artes y bonor de los artesanos. Madrid: Antonio de Sancha, 1778.

15. [CAPMANY y de MONTPALAU, Antonio de]. Discurso político-económico sobre la influencia de los gremios en el Estado, en las costumbres populares, en las artes y en los mismos artesanos. En Semanario erudito. Madrid: Blas Román, X (1788), pp. 173-224. En notas posteriores, subsanaremos una numeración duplicada por error de las páginas iniciales citándolas como 173. ${ }^{2}-176$ a y 173b-176b, respectivamente.

16. SÁnChez Agesta, Luis. "La apología de los gremios de Capmany». Archivo de Derecho Público (Universidad de Granada), 1949, II, pp. 61-109. Más recientemente, ha sido detectada otra prueba a favor de la precedencia cronológica del Discurso político-económico: la incorporación prácticamente literal de las ideas de Helvétius (L’Homme, 1771) a propósito del "plaisir de prévoyance» en el Discurso económicopolítico (Dítz, Fernando. "El gremialismo de Antonio de Capmany (1742-1813). La idea del trabajo de un conservador ingenuom. Historia y política. Ideas, procesos y movimientos sociales. Madrid, 2001, 5, p. 174).

17. Capmany. Discurso político-económico..., p. 194. Son interesantes y muy representativos de la manera de proceder de Capmany con sus textos los matices y juegos de compensación visibles en la otra versión, donde, si por un lado el "problema político" se rebaja a la categoría de "económico" y se abandona el concepto de "enseñanza" - caballo de batalla de Campomanes- en provecho del inocuo término "propagación", utilizado también por el ministro asturiano, por el otro se reivindica con habilidad y gran ambición la categoría de Barcelona como capital industrial de España: "Digo, pues, que este problema económico de la necesidad de los gremios para el honor, conservación y propagación de las artes tiene hasta aquí todos los hechos a su favor, y sólo las especulaciones en contra; porque en esta materia la eloqüencia nada prueba, y la experiencia lo explica todo. Los efectos de los oficios incorporados y demarcados los hemos visto en toda Europa, y hoy los vemos en Londres, Paris y Barcelona, talleres florecientes de las artes de Inglaterra, Francia y España; los de las artes errantes, oscuras y desunidas están por verse» (Discurso económico-político..., p. 48). 
ANTONIO DE CAPMANY Y LA CIUDAD DE BARCELONA: EL VALOR DE LO EMPÍRICO...

En el Discurso económico-político se eliminó, desde el título mismo, el enfoque de la primera parte de la versión primitiva: «La influencia de los gremios en el Estado». No es de extrañar que, con el antecedente próximo del Motín de las Quintas, esa apelación inicial del Discurso político-económico al interés del Estado en la conservación de los gremios urbanos vaya referida al orden público, a "la buena policía» que descansa sobre "la armonía de una sociedad bien organizada»" No se puede decir que el contradictor de Campomanes esconda la cabeza debajo del ala o se sirva de eufemismos:

La historia de los tumultos populares en todos los reynos y provincias es antigua, larga y triste de referirse. Las ciudades grandes han sido siempre más expuestas, no porque su pueblo estuviese distribuido en cuerpos de industria -porque sólo son una separación política de la multitud laboriosa-, sino porque es numeroso, y porque las tormentas del océano son más terribles que las del lago de Ginebra ${ }^{19}$.

A partir de la evidencia del riesgo político que suponen siempre las concentraciones humanas, Capmany desarrolla la teoría de que son más peligrosas las masas no organizadas que una población distribuida en estamentos bien definidos, sirviéndose de una imprecisa e inexacta referencia a la lejana Turquía. Acaso el escritor barcelonés procurase eludir con esta maniobra la mención de ejemplos más cercanos y dolorosos, como podría ser el Madrid del Motín de Esquilache, sin dejar, por otro lado, de poner ante los ojos del ministro los efectos nefastos que podría entrañar, precisamente en la conflictiva capital de Cataluña, la implantación de su ideal liberalizador de todas las actividades económicas:

... qualquiera que sea el principio de estos movimientos, los ciudadanos siempre se pueden amotinar, ya incorporados, ya desunidos; y en Turquía, donde no hay gremios ni artes, suceden todos los días. A lo menos, donde hay gremios tiene el gobierno unos medios ya establecidos que, mejorados en la parte que tengan defectuosa, pueden en las manos de la autoridad pública asegurar la obediencia, la tranquilidad y el buen orden de un pueblo con muchísima más eficacia y facilidad que en las ciudades donde el pueblo sufre una anarquía económica y política ${ }^{20}$.

Según Capmany, la buena marcha del Estado no admite tampoco, hablando en términos económicos, la confusión de clases preconizada en la especulación de Campomanes sobre la "industria popular», donde la población rural debería alternar las labores agrícolas con las artesanas. La agricultura requiere la diseminación

18. Capmany. Discurso político-económico..., p. 176a.

19. Capmany. Discurso político-económico..., p. 174b. Texto no conservado en el Discurso económico-político...

20. Capmany. Discurso político-económico..., p. 175b. Texto no conservado en el Discurso económico-político. . 
de los labriegos por el territorio ${ }^{21}$, mientras que cualquier industria que supere lo rudimentario exige la continuidad del trabajo especializado y la concentración de los artífices en núcleos de población grandes y organizados. El disfrute de garantías jurídicas para el acceso de labriegos y artesanos a los requisitos indispensables en sus labores respectivas -la tierra cultivable, en un caso, y el título profesional, en el otro- es el factor que estimula la sedentarización y la reproducción biológica de ambos grupos humanos y, a la vez, evita su participación en los desórdenes públicos:

El hombre sin propiedad nada posee; el que nada posee, nada tiene que perder, y el que no tiene qué perder, no tiene patria. Este hombre es el labrador sin tierra y el artesano sin cuerpo $^{22}$.

Tal vez no sea inútil aducir aquí el aire de familia de esta combinación de ideas con otra expresada poco antes, en 1770, por uno de los más audaces pensadores de la Ilustración francesa:

Il n'est point de patrie sans bien-être; une société sans équité ne renferme que des ennemis, une société opprimée ne contient que des oppresseurs et des esclaves; des esclaves ne peuvent être citoyens; c'est la liberté, la propriété, la sûreté qui rendent la patrie chère, et c'est l'amour de la patrie qui fait le citoyen ${ }^{23}$.

El autor barcelonés se explaya en la glosa de los gremios como cuerpos intermedios dentro de la organización del Estado, no sólo en calidad de garantes del orden público, sino también como factores de arraigo y autocontrol de las actividades productivas, poniendo coto a un aspecto de la libertad humana que equivaldría a dilapidación de fuerzas:

Cien gremios, por ejemplo, que componen cinqüenta mil personas de artífices, tanto más propensas a la libertad quanto son más dispuestas a la transmigración, porque consigo llevan siempre el pan en su oficio, pueden ser gobernados y zelados por medio de cien cabezas que, sin dispendio del Erario ni menoscabo de las artes, exonerarán al gobierno de una inspección inmediata, embarazosa y diaria sobre la conducta fabril y doméstica de los ciudadanos ${ }^{24}$.

21. Capmany. Discurso político-económico..., pp. 176a-173b. El largo párrafo dedicado a la condición labriega, especialmente polémico con las disquisiciones del Discurso sobre el fomento de la industria popular, es uno de los eliminados en el Discurso económico-político..

22. Capmany. Discurso político-económico..., p. 175b. Esta frase, que culmina y cierra formalmente la primera parte de la obra y que es la cita de Capmany preferida por Sánchez Agesta, es desplazada en la publicación de 1778 al interior de un largo párrafo que parece destinado a disimular su contundencia (Discurso económico-político..., p. 23).

23. [D'Holbach, Paul Henri Thiry, barón]. Système de la nature, ou des loix du monde physique et du monde moral. Londres, 1770, vol. I, p. 164.

24. Capmany. Discurso político-económico..., p. 173b. Versión mucho menos explicativa en el Discurso económico-político..., p. 4. 
ANTONIO DE CAPMANY Y LA CIUDAD DE BARCELONA: EL VALOR DE LO EMPÍRICO...

En el combate contra la confianza de Campomanes en que la apertura indiscriminada de las fronteras a los artesanos extranjeros -obstaculizada hasta el momento por los privilegios gremiales- obraría el milagro de regenerar la economía de España y acrecentaría su población y el poder del Estado ${ }^{25}$, Capmany subraya el valor de la asociación sedentaria de los trabajadores y la convierte en un rasgo de naturaleza sirviéndose de una analogía en el reino animal tomada de una controvertida teoría del naturalista Buffon:

Sepárense los artífices, sin relaciones, interés ni comunidad, y su industria, inteligencia y actividad se verán espirar, como las de los castores, dispersos, perseguidos y errantes ${ }^{26}$.

\section{EL VIRAJE HISTORIOGRÁFICO}

En 1779 Capmany emprendió, bajo el patrocinio de la Junta de Comercio de Barcelona, la edición de sus Memorias históricas sobre la marina, comercio y artes de la antigua ciudad de Barcelona, cuyos dos volúmenes -uno con el texto principal y otro con una colección diplomática y diversos apéndices- quedaron completados en $1781^{27}$. En relación con las dos versiones del Discurso levantado contra la directriz antiurbana de Campomanes, la nueva empresa literaria no entrañó cambio de intenciones ni de argumentos. Ahora bien, de unas especulaciones

25. Simétricamente, el abogado general del Parlamento de Paris, Antoine-Louis Séguier, en la célebre sesión donde triunfaron los criterios de Turgot, expresó los temores a que la liberalización condujese a la emigración de los artesanos franceses hacia países necesitados de su habilidad y menos exigentes en cuanto a requisitos de fabricación (Procès-verbal..., pp. 88-89). DESDEVISES DU DÉZERT, Georges. L'Espagne de l'Ancien Régime. Paris: Société française de l'imprimerie et de librairie, 1904, vol. III, p. 51, dijo de pasada que los argumentos de Capmany se parecían a los de Séguier, pero ni siguen los mismos derroteros ni las fechas de los escritos respectivos respaldan la idea de una influencia directa, que algunos autores modernos han continuado sugiriendo.

26. Capmany. Discurso político-económico..., pp. 192-193. Versión equivalente en el Discurso económico-político..., p. 44. Según Buffon, en los territorios muy frecuentados por los hombres, como los europeos, "les castors y sont, comme tous les autres animaux, dispersés, solitaires, fugitifs, ou cachés dans un terrier", mientras que, en un contexto de densidad humana baja, como en América del Norte, "on a partout trouvé les castors réunis, formant des sociétés, et l'on n'a pu s'empêcher d'admirer leurs ouvrages»; de lo cual deduce que la presión humana sobre las especies animales ha causado en éstas una desaparición de sus rasgos superiores (BufFOn, Georges-Louis de Leclerc, conde de. Histoire naturelle, générale et particulière. Paris: Imprimerie Royale, 1760, vol. VIII, p. 286).

27. Capmany y de Montpalau, Antonio de. Memorias históricas sobre la marina, comercio y artes de la antigua ciudad de Barcelona. Madrid: Antonio de Sancha, 1779, 2 vols. [cada parte de la obra tiene su propia paginación, en romanos o arábigos]. Entre 1790 y 1792 Capmany produjo otros dos volúmenes, con la misma disposición general pero una estructura más laxa: Suplemento a las Memorias históricas sobre la marina, comercio y artes de la antigua ciudad de Barcelona. Madrid: Imprenta de Sancha, 1792, 2 vols. Simultáneamente dio a la luz un estudio y publicación documental complementarios: Código de las costumbres marítimas de Barcelona, hasta aquí vulgarmente llamadas Libro del Consulado. Madrid: Antonio de Sancha, 1791, 2 vols. 
racionales asentadas en una evidencia empírica presuntamente abrumadora, aunque invocada con tanto énfasis como inconcreción deliberada, se pasó a una aportación de informaciones contrastadas referidas a la ciudad de Barcelona y a propósito de un período, la Baja Edad Media, separado cronológicamente del tiempo presente, pero cuya impronta Capmany exalta como fundamental para la caracterización de la urbe y para sus expectativas actuales, apoyado en una teoría histórica naciente que había de tener un largo recorrido en la cultura occidental.

\subsection{La teoría del progreso y las ciudades medievales}

En el preámbulo del Discurso político-económico, dedicado a la «Definición del pueblo en general», Capmany afirma que «el gobierno gótico degradó y borró en las edades de hierro" al pueblo artesano y que correspondió a las ciudades italianas el mérito de su restauración ${ }^{28}$. El camino que une esa primera experiencia de emancipación del pueblo trabajador refugiado en las ciudades medievales y el progreso moderno auspiciado por los Estados es glosado con más amplitud en el Discurso económico-político:

Las instituciones gremiales tomaron su origen en las ciudades populares de Italia de la Media Edad, quando el senador se hacía artesano y el artesano senador. Sobre aquel sistema libre y jurisprudencia consular, de que siempre han necesitado el comercio y las artes, sus compañeras, se formaron éstas, crecieron, prosperaron y florecieron, haciendo de las ciudades de la Lombardía y la Toscana el taller universal de las manufacturas de aquellos siglos. Baxo el nombre y orden de corporación o comunidad, se plantificaron los oficios en Flandes, Francia y últimamente en Inglaterra; en cuyos países han llegado las artes al último punto de esplendor y perfección sin embarazo alguno ${ }^{29}$.

Desde el punto de vista estrictamente historiográfico, el objetivo de las $\mathrm{Me}$ morias históricas es la incorporación de Barcelona a esa genealogía del progreso, inseparable de la institucionalización de la economía productiva y del principio de la libertad civil. Como la finalidad práctica declarada, tanto de esta obra como de sus antecesoras inmediatas, es el fomento de la riqueza de España y el poder de su monarquía, Capmany invoca repetidamente el ejemplo de Inglaterra, la potencia rival de los Borbones españoles, hegemónica en Europa y en los océanos después del Tratado de Utrecht. Tal vez el análisis que del gran éxito británico había hecho Voltaire en sus Réflexions sur les anglais fue la fuente inspiradora de la estructura argumental de las Memorias históricas, que relaciona dialécticamente el comercio, la libertad civil y la grandeza del Estado, con especial énfasis en el poderío naval:

28. Capmany. Discurso político-económico..., p. 175a.

29. Capmany. Discurso económico-político..., p. 44. 
Le commerce, qui a enrichi les citoyens en Angleterre, a contribué à les rendre libres, et cette liberté a étendu le commerce à son tour; de là s'est formée la grandeur de l'État. C'est le commerce qui a établi peu-à-peu les forces navales, par qui les anglais sont les maitres des mers ${ }^{30}$.

La libertad civil y sus secuelas políticas habían sido abordadas en el Discurso político-económico con grandes precauciones y buscando efectos a corto plazo.

Por un lado, de acuerdo con su adscripción al empirismo, y en el esfuerzo por hacerla aceptable para los gobernantes absolutistas, el joven Capmany no presentaba ahí la libertad como un principio absoluto e invariable a través de los tiempos, sino, ante todo, como una percepción psicológica originada al amparo de la compartimentación estamental y cuya benéfica reproducción se debería seguir garantizando dentro de la misma:

... una ilusión de libertad, que no es otra cosa que la de no ser un ciudadano juzgado por éste sino por esotro que conozca mejor sus intereses. Hágase que los soldados dependan de los letrados, y entonces veremos confundido el paisano y el soldado, y nulos el fuero y estimación militares ${ }^{31}$.

Por el otro, concedía que la participación política popular quedase circunscrita al reducido ámbito del compartimento gremial, aunque desde 1766 los consistorios municipales de España habían abierto sus puertas a ese estamento; y particularmente en Barcelona, la figura de los diputados y síndicos personeros del común fue objeto de una adaptación en beneficio directo de las corporaciones:

En una monarquía donde el pueblo no tiene parte en los empleos y en los honores, reservados sólo a cierta clase de personas, es más necesario un gremio que circunscriba en aquella pequeña sociedad toda su codicia y ambición ${ }^{32}$.

Pero en las Memorias históricas, que hablan del pasado medieval y no del presente, la participación de los agremiados en los cargos municipales emerge sin disimulo como el punto clave del prestigio social de sus actividades:

... como los menestrales formasen desde los principios una porción considerable de los vecinos de las ciudades y villas y de los individuos que componían su cuerpo

30. Voltaire. Oeuvres. Amsterdam: É. Ledet et cie, 1739, vol. IV, p. 213. Dice Touchard que «este texto de Voltaire define el ideal de una clase. Plantea en términos precisos las cuatro ecuaciones que constituyen, para la burguesía europea, el ciclo del progreso» (Touchard, Jean. Historia de las ideas políticas. Madrid: Tecnos, 1964, p. 301). Sobre la estructura del primer volumen de las Memorias históricas: GRAU I FERNÁNDEZ, Ramon. "Antonio de Capmany i la teoria marítima de Barcelona». En Grau, Ramon (coord.). Barcelona i el mar. Homenatge a Antoni de Capmany, 1742-1813. Barcelona: Ajuntament de Barcelona, 2014, (Barcelona Quaderns d'Història, 21), pp. 19-42.

31. Capmany. Discurso político-económico..., p. 176b. Sin equivalencia en el Discurso económico-político..

32. Capmany. Discurso político-económico..., p. 192. Versión semejante en el Discurso económico-político..., p. 14. 
consistorial, el honor y distinción de sus puestos honró los oficios y profesiones mecánicas ${ }^{33}$.

Abandonadas las precauciones seguidas en el doble Discurso, aflora de manera explícita el principio de la libertad como deus ex machina. En efecto, Capmany establece que

... para adquirir las artes un establecimiento fixo y constante fue menester que la libertad, madre de la civilización, hubiese roto antes las duras cadenas de la segunda edad de hierro. El espíritu de industria estaba extinguido en toda Cataluña en los primeros siglos en que rigió el systema feudal con todo el rigor de su institución: ¿pues acaso las máximas mezquinas y tiránicas de una aristocracia como era la de los primitivos condes podían ser favorables al arraygo de las artes? Lo cierto es que éstas no podrían hallar abrigo ni fomento mientras no hubiese hombres libres que las pudiesen exercer con la seguridad y propiedad que exigen los oficios, entonces incompatibles con la condición de los siervos del terreno ${ }^{34}$.

Hay que advertir que el historiador barcelonés, escrupuloso en la documentación de las series de hechos expuestos en los capítulos específicos del primer volumen de sus Memorias históricas, en los pasajes consagrados a su encuadre histórico dentro de la evolución europea no apuntala la transferencia de explicaciones elaboradas sobre la experiencia de los países del entorno al caso catalán con referencias explícitas a una bibliografía que sin duda le hubo de inspirar.

La peripecia de las ciudades lombardas y toscanas, sujetas al Sacro Imperio, en su lucha por la obtención de las libertades cívicas, entre la minoría de Otón III a fines del siglo X y la época de Enrique IV, cien años más tarde, había sido estudiada seriamente en la primera mitad del siglo XVIII por Ludovico Antonio Muratori, cuya magna publicación de fuentes narrativas fue, por otro lado, la base principalísima de Capmany para documentar la actividad marítima de los catalanes en el marco del Mediterráneo bajomedieval. Ahora bien, su influencia en la interpretación del afloramiento de las libertades ciudadanas en Cataluña no es tan marcada, debido posiblemente a que el propio Muratori tuvo cuidado de señalar las peculiaridades del Imperio, vasto, diverso y con un poder supremo inestable y controvertido, e indicar que las ciudades de Italia, primero, y las de Germania, después, alcanzaron, gracias a esa debilidad estructural, una plena autonomía republicana que no se pudo dar en Francia. Ahí también «si formarono dei comuni, ma dipendenti dal re e dai magistrati suoi, o dai duchi, marchesi e conti di quelle contrade ${ }^{35}$.

33. CAPMANY. Memorias históricas..., vol. I-Artes, p. 5.

34. Capmany. Memorias históricas..., vol. I-Artes, p. 3.

35. Muratori, Ludovico Antonio. Dissertazioni sopra le antichità italiane. Roma, 1755 (publicación póstuma), vol. III-1, XLV. Dalla forma di repubblica presa da moltissime città d'Italia, e dell'origine della loro libertà, p. 14. 
Capmany vincula el caso barcelonés al contexto de la monarquía francesa, de cuyo tronco se había desprendido Cataluña al final de la etapa carolingia. Las populares Observations sur l'histoire de France publicadas en 1765 por el abate Mably, admirador de Rousseau, pudieron proporcionar a Capmany los datos históricos más relevantes así como la interpretación de los mismos. En efecto, mientras que el erudito Muratori distingue entre la emancipación de las ciudades italianas respecto del poder imperial, momento en que "ordinariamente i nobili sono quei che regolano il comune a nome di tutto il popolo» ${ }^{36}$, y la posterior entrada del estamento popular en los gobiernos comunales, el más sintético y mucho menos escrupuloso Mably está simplemente interesado en establecer la confrontación de principio entre las ciudades y el universo feudal y convierte a los burgueses en protagonistas de la vida política comunal desde el origen de los municipios. La construcción de Capmany participa de esta mitificación democrática, y, en todo caso, la influencia directa de Mably es detectable, como mínimo, en el pasaje de las Memorias históricas que describe los efectos psicológicos de la emancipación popular. Dice Mably:

Dès que quelques villes eurent traité de leur liberté, il se fit une révolution générale dans les esprits. Les bourgeois sortirent subitement de cette stupidité où la misère de leur situation les avoit jetés ${ }^{37}$.

\section{Y recoge Capmany:}

... la comunicación de esta libertad civil ocasionó una transformación tan feliz en todos los individuos de las universidades o comunes, que bien presto salieron de aquel estado de estupidez e inacción en que los tenían antes sepultados la opresión y la servidumbre ${ }^{38}$.

No obstante, el apologista catalán de la democracia municipal y de la monarquía pactista no sigue las originales elucubraciones de Mably a propósito de Luis el Gordo, a quien el abate concedía el mérito de haber emancipado al estamento popular en la primera mitad del siglo XII, no sin preguntarse si dicha acción respondería a una generosa visión a largo plazo o a estímulos crematísticos de interés más inmediato y efectos bien palpables:

Peut-être comprit-il, ce qui demanderoit un effort de raison bien extraordinaire dans le siècle où ce prince vivoit, qu'en rendant ses sujets heureux il se rendroit lui-même plus puissant et plus riche. Peut-être ne traita-t-il avec ses villes de leur liberté que gagné par l'appas de l'argent comptant qu'on lui offrit; et dans ce cas-là même, il faudroit encore le louer de ne l'avoir pas pris sans rien accorder. Quoiqu'il en soit,

36. Muratori. Dissertazioni..., vol. I, XVIII. Della repubblica e parte pubblica, e de'suoi ministri; e se le città città d'Italia avessero anticamente comunità come oggidì, p. 203.

37. Mably, Gabriel Bonnot, abbé de. Observations sur l'histoire de France (1765). En Oeuvres complètes. Londres, 1789, vol. II, p. 56.

38. Capmany. Memorias bistóricas..., vol. I-Artes, p. 4 
il rendit son joug plus léger et leur vendit comme des privilèges des droits que la nature donne à tous les hommes; c'est ce qu'on appelle le droit de commune ou de communauté39.

Siempre atento al efecto que la lectura de sus escritos podría surtir en el ánimo de Carlos III y de sus ministros, el Capmany de las Memorias históricas evita, siempre que puede, hablar de los móviles de los monarcas en términos tan crudamente materialistas.

La síntesis de Capmany, que transfiere a la figura de Ramon Berenguer IV las acciones atribuidas por Mably a Luis VI, es más bien tributaria de la que se puede leer en la visión panorámica sobre la Edad Media trazada en 1769 por un buen conocedor y seguidor tanto de Muratori como de Mably, el gran historiador escocés William Robertson:

Louis le Gros, in order to create some power that might counterbalance those potent vassals who controuled or gave law to the crown, first adopted the plan of conferring new privileges on the towns situated within its own domaine. These privileges were called charters of community, by which he enfranchised the inhabitants, abolished all marks of servitude, and formed them into corporations or body politic, to be governed by a council and magistrates of their own nomination ${ }^{40}$.

La adaptación catalana es como sigue:

Pero como desde el siglo XII el conde de Barcelona Raymundo IV, empeñado en contrabalancear el poder de los barones, que oponían un fuerte antemural contra el exercicio soberano del príncipe, adoptase el pensamiento, ya imaginado entonces por otros soberanos de Europa, de conceder nuevos privilegios a las ciudades situadas en su dominio patrimonial, la industria buscó luego aquellos asilos, que empezaron a ser el centro y patria común de todos los hombres libres ${ }^{41}$.

Como es perceptible, Capmany articula la visión sobre la operación antifeudal en las esferas de la alta política, extrayéndola de la bibliografía europea, con la de sus efectos económicos y sociales, no siempre resaltada en aquellos contextos discursivos pero que, para él, como buen barcelonés, eran un punto del mayor interés.

En cierta manera, el mismo Robertson, atento a la historia de la península Ibérica y especialmente a la de la Corona de Aragón, avala la adaptación de sus tesis ejecutada por el autor catalán al indicar que la estrategia de aquel monarca francés se extendió a los otros Estados feudales de Europa y subrayar explícitamente el

39. MABLy. Observations..., pp. 53-54.

40. ROBERTSON, William. The History of the reign of the Emperor Charles V (1769); edición: Londres: Strahan, 1802, vol. I, A view of the progress of society in Europe from the subversion of the Roman Empire to the beginning of the sixteenth century, p. 39.

41. Capmany. Memorias históricas..., vol. I-Artes, p. 3 
caso de España en primer lugar ${ }^{42}$. Y aunque lamenta que «the Spanish historians are almost entirely silent concerning the origins and progress of communities", puede extraer de Jerónimo Zurita la noticia sobre las excepcionales libertades otorgadas a los ciudadanos de Zaragoza en 1118:

In the year 1118, the citizens of Saragossa had not only attained political liberty, but they were declared to be of equal rank with the nobles of the second class; and many other immunities, unknown to persons in their rank of life in other parts of Europe, were conferred upon them ${ }^{43}$.

Sin duda, ello fue un estímulo para que Capmany convirtiese la exaltación del régimen municipal barcelonés como gobierno popular y de la primacía de Barcelona entre las ciudades de la Corona de Aragón en el clímax de la «Descripción de Barcelona» que preside el primer volumen de las Memorias históricas:

Pero lo que principalmente contribuyó en los siglos pasados a la alta consideración de la ciudad de Barcelona, cuyo nombre habían llevado las armas y el comercio hasta los fines de la tierra, fue la forma de su gobierno popular, la sabiduría de sus leyes y la pureza y austeridad de sus costumbres. Y como cada día esta capital mereciese mayores gracias de la munificencia de sus reyes, llegó a ser la ciudad de mayor importancia de la Corona, modelo y exemplo de todas las demás en su administración municipal, buscada por las principales repúblicas y por los mayores potentados de la Europa, como mediadora con sus príncipes; y cuya influencia, por su libertad, servicios y poder, decidía muchas veces de la paz y de la guerra entre las naciones mercantiles ${ }^{44}$.

En un apéndice del volumen segundo se traza la evolución de ese sistema de gobierno de la ciudad de Barcelona, empezando por la fase de administración a cargo de delegados del soberano, primero el rey de Francia y después los condes, quienes «concedieron luego al pueblo barcelonés la facultad de congregarse» en concejo abierto; para pasar, a raíz de la unión dinástica con Aragón, a un consistorio formado por los prohombres, y luego a los ensayos de "nueva planta" sancionados por Jaime I en 1249 y 1257, fecha en que el cuerpo municipal quedó constituido por "Ocho concelleres y un senado de doscientos prohombres». Aunque esta composición fue alterada por dos veces bajo el mismo monarca, Capmany considera que el principio fundamental había quedado ya consolidado entonces de manera irreversible:

Éste fue el origen de la constitución democrática que conservó siempre el gobierno económico de aquella universidad, y la que el pueblo barcelonés reclamó todas

42. "The practice spread quickly over Europe, and was adopted in Spain, England, Scotland and all the other feudal kingdoms" (ROBERTSON. The History of the reign..., vol. I, p. 40).

43. ROBERTSON. The History of the reign..., vol. I, pp. 315-316.

44. CAPMANY. Memorias históricas..., vol. I-Marina, pp. 7-8. 
las veces que vió alterarse esta primitiva forma en menoscabo de sus antiguos derechos ${ }^{45}$.

En el mismo lugar se traza la más completa y ponderada descripción de esa "constitución democrática» de que Capmany fue capaz, teniendo en cuenta que le importaba más transmitir una síntesis tipológica que debilitarla con la cronología detallada de su desarrollo. Eso salta aquí a la vista, precisamente porque parte del pulcro Muratori y de su descripción de la entrada de los artesanos en el gobierno de Génova en 1339, a la que relaciona con la democratización instigada por la Corona y producida en el municipio de Barcelona un siglo más tarde, en 14521455; ambas, en todo caso, corrigiendo un régimen hasta entonces de carácter oligárquico:

Lo mismo a poca diferencia leemos de las ciudades de Pavía, Florencia, Sena y otras que por aquellos tiempos adoptaron esta forma popular de gobierno electivo, distribuído entre las diferentes clases de sus ciudadanos y de los oficios mecánicos. Una ciudad como Barcelona no hubiera podido perfeccionar y hacer respetable su administración económica si los reyes, en reconocimiento y para mayor estímulo de sus generosos servicios, no la hubiesen comunicado muchas regalías y concedídole singulares prerrogativas, justamente en tiempos en que, recelosos de la independencia y poder de los barones, procuraban los príncipes hacer de sus ciudades asilos de los hombres libres y centro, por consiguiente, del comercio y de las artes.

Barcelona, pues, gozó alguna vez de toda la actividad de una monarquía y de toda la prudencia de una república, y sus moradores eran soldados intrépidos al paso que ciudadanos austeros. Baxo la sombra de unos reyes poderosos y acostumbrados a vencer sus enemigos, mantenía esta capital toda la libertad que necesitaba para engrandecerse y hacer su prosperidad, y ninguna para hacerse daño; pues, siendo sus propios monarcas sus supremos moderadores, los abusos que nacían de su forma mixta de gobierno se reformaban o cortaban al mismo tiempo que aparecían. Por este medio llegó Barcelona, siendo una ciudad mediana, a adquirirse en todo el Mediterráneo tanta influencia, autoridad y nombre como Venecia y la misma Génova ${ }^{46}$.

\subsection{Las inflexiones de la Edad Moderna y la continuidad de la ética ciudadana}

Es más que notable la aplicación de las teorías de la naciente historiografía liberal en una obra como las Memorias históricas, dedicada por su autor a un monarca absoluto como Carlos III de Borbón. No obstante, como acabamos de ver, Capmany ofrece una imagen histórica de la Barcelona medieval, incluida su tendencia republicana, en armonía siempre con los intereses materiales de la

45. CAPMANY. Memorias históricas..., vol. II-Apéndice, núm. XXIV, Idea histórica del origen y naturaleza del antiguo gobierno municipal de la ciudad de Barcelona, pp. 67-68.

46. Ibidem, p. 71. 
monarquía. La conciliación se completa, más allá del período objeto de su retrato tipológico de la ciudad medieval, con un recurso a las mismas fuentes doctrinales.

Efectivamente, Capmany enlaza con las ideas del propio Robertson por lo que respecta al siglo XVI, centro de atención principal de las tres grandes monografías del británico, de alcance cada vez más amplio, que versan, respectivamente, sobre una Escocia accediendo al concierto de las naciones justo antes de entrar en la órbita de Inglaterra, sobre el Continente bajo el último esfuerzo de unificación imperial protagonizado por Carlos V y sobre la expansión europea en el Nuevo Mundo ${ }^{47}$. Por su parte, el historiador catalán identifica y menciona repetidamente a lo largo de su obra los cambios geopolíticos consumados a principios del Quinientos que socavaron los fundamentos de la actividad mercantil de Barcelona y Cataluña y erosionaron la entidad política de ambas: el descubrimiento de América, la conquista otomana de Siria y Egipto y la gran unión dinástica bajo el célebre nieto de Fernando el Católico ${ }^{48}$. Y por ello, cierra el plan de sus Memorias históricas en ese momento:

A la verdad aquel siglo fue el de las grandes revoluciones políticas: unas naciones acabaron de hacer su papel en el teatro de los mares para ceder su lugar a otras que empezaron su carrera con más osadía o más fortuna que las que las habían dado las luces y el exemplo ${ }^{49}$.

Esta alusión no se refiere principalmente a España -como tal vez estuvieron o estarían inclinados a interpretar lectores de épocas posteriores- sino a Inglaterra. A la luz del moderno triunfo de esta potencia bajo su régimen de libertades, Capmany teje un discurso que aloja en su seno una apreciable carga crítica contra la teoría y la práctica del absolutismo monárquico, aunque no puede dejar de seguir la senda del grueso de los autores -principalmente franceses- encuadrables en el progresismo de su tiempo e interpretar la concentración de poder territorial en Europa a partir del siglo XVI, e incluso la consumada de manera bien traumática en la Barcelona de 1714, como pasos en el camino hacia la plenitud de la Humanidad:

Pero al fin aquella forma de gobierno republicano, que pudo ser útil en las circunstancias de aquellos siglos en que los reyes eran pequeños y pobres, y las fuerzas de mar y tierra se medían por los subsidios de las ciudades y de la nobleza, hubo de degenerar en un perpetuo conflicto de potestades desde que la monarquía española, acabada de formar de diversas provincias, o más bien naciones, empezó

47. Las monografías históricas de William ROBERTSON aludidas son: la History of Scotland, de 1759; The History of the reign of the Emperor Charles V, de 1769; y la History of America, de 1779. Véase la interpretación de MeINECKE, Friedrich. Die Entstebung des Historismus. Berlín, 1936, vol. I, p. 260 (versión castellana: El historicismo y su génesis. México: Fondo de Cultura Económica, 1943, p. 206), que presenta esa trilogía como un desarrollo de la Idée générale du seizième siècle que constituye el capítulo 118 del Essai sur les moeurs de Voltaire.

48. Capmany. Memorias históricas..., vol. I-Marina, p. 182.

49. CAPMANY. Memorias históricas..., vol. I-Prefación, p. XXIII. 
a trabajar en consolidarlas para establecer un solo poder e interés nacional, cuya beneficencia y vigilancia fuesen difusivas a todas las partes del cuerpo político ${ }^{50}$.

Por debajo de este proceso de refundición política al parecer inevitable, Capmany insiste en el valor positivo del rastro dejado por los tres siglos bajomedievales en las costumbres y el carácter catalán.

Con frecuencia, las tesis sobre valores sociales expresadas en abstracto en el doble Discurso contra Campomanes cobran su plena significación cuando afloran en las Memorias históricas referidas concretamente a Barcelona y a los catalanes. La imagen de los castores, inteligentes sólo cuando pueden asociarse sin ser hostigados por los humanos, es aplicada en el primer volumen de esa obra para remachar el clavo de la persistencia de la capacidad productiva de la ciudad de Barcelona desde el siglo XIII hasta el mismo XVIII y reclamar implícitamente una benevolente inhibición del poder político, delatando así la impostación del tono genérico adoptado en aquel Discurso:

... los gremios, según lo ha mostrado la experiencia de cinco siglos continuados, han hecho un bien incomparable en Barcelona, sólo con conservar como en depósitos inmortales el amor, tradición y memoria de las artes. Ellos han formado otros tantos puntos de reunión, digámoslo así, baxo cuyas vanderas se refugiaron algunas veces las reliquias de la industria para repararse, rehacerse y sostenerse hasta nuestros tiempos, a pesar de las pestes, guerras, facciones y otras funestas calamidades que agotan los hombres, transtornan los domicilios y alteran las costumbres. Si Barcelona, que ha padecido tantos de estos azotes físicos y políticos, hubiese tenido sus artífices dispersos, sin comunidad, interés ni relación entre sí, toda su inteligencia, economía y actividad hubieran seguramente desaparecido, como sucede a los castores perseguidos del cazador quando llegan a desunirse ${ }^{51}$.

Y en el Suplemento de 1792, donde los argumentos antropológicos suelen aparecer reforzados, la presentación de la misma imagen adopta una forma que ha sugerido a Ernest Lluch que Capmany debió de escribirla recordando todavía el resultado mediocre que dieron los colonos catalanes en Sierra Morena ${ }^{52}$.

La nueva frase, muy fiel a las ideas de Buffon, encaja, en cualquier caso, con las doctrinas de Montesquieu y de sus seguidores a propósito de la influencia de las condiciones ambientales sobre el individuo:

Los catalanes son industriosos por espíritu de imitación, reunidos en pueblo, en comunidad nacional, es decir, en el seno de sus familias, a la vista de otros que les ayuden con su exemplo; semejantes a los castores, cuya industria maravillosa

50. Capmany. Memorias históricas..., vol. I-Marina, p. 8.

51. CAPMANY. Memorias históricas..., vol. I-Artes, p. 34.

52. Lluch, Ernest. El pensament econòmic a Catalunya (1760-1840). Barcelona: Edicions 62, 1973 , p. 44 
queda reducida a un instinto puramente pasivo quando se les dispersa y desune de su sociedad 53 .

Poco antes, en la misma página, puede leerse:

Un catalán de tierna edad, criado o trasplantado en país de haraganes, se vuelve haragán y contrae los vicios o falsas ideas de los que le rodean.

Por su parte, D'Holbach decía:

Un européen transplanté dans l'Indostan deviendra peu-à-peu un homme tout différent pour l'humeur, pour les idées, pour le tempérament et le caractère ${ }^{54}$.

Un aspecto de singular importancia dentro del Discurso político-económico era la invocación de las economías de escala generadas por los gremios urbanos, apuntando a un efecto nada desdeñable de esos amplios conglomerados de productores, como es el servicio que pueden prestar a las ambiciosas empresas de la monarquía:

Los gremios, como cuerpos poderosos, dirigidos por unanimidad de inteligencia y comunidad de intereses, hacen con ventaja y oportunidad los acopios de las materias primeras, proveen las necesidades de los maestros, adelantan, fian a sus individuos, que carecen de fondos y tiempo para emprender estas anticipaciones por sí. Los cuerpos de oficios emprenden abastos y rápidas expediciones, promueven fábricas, costean máquinas y dan un gran impulso a la industria y al comercio en general. Las empresas de la Corona, por vastas, difíciles y executivas que sean, hallan en la economía y actividad de estos cuerpos inteligentes y bien organizados todo el servicio y desempeño posibles ${ }^{55}$.

Esta última afirmación genérica halla de nuevo su referente concreto en las Memorias históricas, escritas cuando la inquietud de la monarquía respecto a la segura posesión de Cataluña había amainado un tanto y en donde Capmany puede ya centrar la atención de sus lectores cortesanos en las aportaciones positivas de la economía barcelonesa a las empresas imperiales de los Borbones:

No habiendo sido, pues, aquella capital el domicilio antiguo y nativo de los oficios, ¿cómo era posible que apenas acabada de salir del azote de quatro sitios, desde 1697 hasta 1714, hubiese venido a ser el taller principal de la industria española? En efecto, si las costumbres laboriosas no hubiesen conservado sin interrupción la tradición y la enseñanza de las artes, ¿podía un viagero francés haber afirmado en 1729 que, siendo los catalanes los mejores artífices de España, muy activos y hábiles, era entonces Barcelona respecto a este reyno lo que Paris respecto a la Francia? Tan

53. Capmany. Memorias históricas..., vol. III, p. 315.

54. D'HolBaCH. Système de la nature..., vol. I, p. 144.

55. Capmany. Discurso político-económico..., p. 202. Versión equivalente en el Discurso económico-político..., p. 49. 
buenas disposiciones de parte de aquellos ciudadanos, que sólo habían carecido de objetos capaces de reanimar sus antiguas artes, hicieron que las tropas españolas se vistiesen y armasen completamente de manufacturas del reyno después de la Guerra de Sucesión, lo que antes se hacía en Italia y Flandes. Podemos decir que en Barcelona se formaron los primeros asientos de esta suerte de empresas, de cuyo pronto desempeño es buen testimonio la expedición a Sicilia del año $1718^{56}$.

\section{Del Pasado al Futuro: El Perfil histórico de Barcelona}

Entre los dos primeros volúmenes de las Memorias históricas y los dos de su Suplemento son apreciables numerosas diferencias, que la similitud del formato no hace sino subrayar. De un argumento complejo pero muy bien trabado, referido estrictamente a la ciudad de Barcelona y que respondía a la voluntad de la burguesía local de responder a las directrices de liberalización económica a toda costa promovidas por Campomanes, se pasa a un contenido mucho menos integrado, misceláneo incluso.

La apremiante polémica de 1779 desarrollada en el plano político cede en buena parte el paso diez años después a los más reposados debates entre eruditos dentro de una asunción personal de las funciones de historiador crítico bajo el imperio del racionalismo empírico. Junto a los temas estrictamente barceloneses o catalanes, Capmany aborda ahora problemas de historia general de la civilización -la capacidad de las naves en las diversas edades de la historia, las invenciones de la brújula y de la pólvora y la aparición de las enfermedades venéreas en Europa-, que le interesaron grandemente, puesto que en 1807 darían cuerpo a las Qüestiones críticas sobre varios puntos de bistoria económica, política y militar, su última publicación erudita.

Estas notorias digresiones son la otra cara de un descubrimiento poco grato. En efecto, al profundizar en el estudio de la economía bajomedieval, Capmany había hallado pruebas punzantes de que los reinos ibéricos, y la propia Barcelona, habían ocupado, en realidad, un lugar muy secundario en el contexto mediterráneo y europeo. Esas pruebas son exhibidas con preocupación en el prefacio del Suplemento, y en el cuerpo de la obra dan lugar a un tratamiento desencantado en torno a la

56. CAPMANY. Memorias históricas..., vol. I-Artes, p. 21. El testimonio francés invocado es el de SilhouetTe, Étienne. Voyages de France, d'Espagne, de Portugal et d'Italie. Paris: Merlin, 1770, vol. IV, Relation d'un voyage de Paris en Italie, Espagne et Portugal, du 22 avril 1729 au 6 février 1730, p. 25: "Les catalans sont les meilleurs ouvriers de toute l'Espagne; ils sont actifs et adroits. Barcelone peut être regardée, par rapport à l'Espagne, comme Paris par rapport à la France; c'est dans Barcelone que l'on fait la plus grande partie des habillemens de troupes et de livrées. Il y a quantité d'orfèvres et toutes sortes d'ouvriers. Les catalans ne sont pas moins bons mariniers que bons artisans». Probablemente, la lectura de Silhouette inspiró a Capmany el enriquecimiento del argumento central contra Campomanes que vemos en la segunda versión de su Discurso, con la equiparación de Barcelona con Paris, que hace extensiva a la capital de Inglaterra (véase el texto reproducido en la nota 17). 
pregunta de «Si las artes e industria de España han igualado en algún tiempo a las estrangeras». Asumida la inferioridad española y catalana en el pasado, una versión enriquecida del mismo capítulo reaparecerá también en las Qüestiones críticas, con un cambio del término de comparación que denota una recuperación del optimismo: "Si la industria, la agricultura y la población de España en los siglos pasados han llevado ventaja a las del tiempo presente». Efectivamente, en el dinamismo demográfico y económico creciente y palpable de Barcelona y su área de influencia desde la década de 1760 hasta principios del siglo XIX irá hallando nuestro ilustrado pensador la respuesta conciliable de nuevo con la teoría del progreso; una respuesta consoladora, aunque no extensible al interior de la península Ibérica.

Aun así, a lo largo de esos años, la conflictiva relación entre el pasado y el presente se manifestaba con fuerza en la transformación física de Barcelona, y el observador Capmany no quiso pasarlo por alto. El dictamen poco halagüeño -y con implicaciones políticas- sobre la arquitectura y las artes barcelonesas publicado por Antonio Ponz en 1788, que excitó su vena de polemista, fue la ocasión para tratar, en el breve pero crucial último capítulo del Suplemento, titulado «De los edificios públicos de la Baxa Edad que se conservan en la ciudad de Barcelona", tanto de la progresiva reducción de la ciudad medieval a la condición de vestigio, como del mérito de los monumentos legados por aquella Edad.

\subsection{La pulcritud de la ciudad medieval y la vertiente destructiva del siglo XVIII}

La "Descripción de Barcelona» que encabeza el primer volumen de las $\mathrm{Me}$ morias históricas es un magnífico ejemplo de preterición propio de un estudioso de la retórica. Descartando por falaces los orígenes míticos de la ciudad, por no conectados con el presente los fastos de la romanidad y por oscuros e inaccesibles los tiempos altomedievales, Capmany centra la atención en la Baja Edad Media para conducir a la apología del gobierno popular, de las leyes municipales y de la austeridad de las costumbres que hemos leído más arriba. El último peldaño antes de ese clímax es la evocación de la belleza de la ciudad medieval y de su entorno, de acuerdo con el testimonio de escritores forasteros de aquellos siglos:

En efecto, la limpieza y enlosado de sus calles y plazas; la hermosura, solidez, elevación e igualdad de sus casas; la magestad y grandeza de sus templos; la alegría y primor de sus barrios y sus jardines, son objetos que ya merecieron en los tiempos pasados el encomio de los geógrafos y viageros. Por otra parte, la amenidad de su territorio, la vista de su apacible campaña, donde siempre han brillado el primor del cultivo y la elegancia de las quintas de recreo, también lograron los elogios que justamente pedían la aplicación y el buen gusto de los antiguos barceloneses ${ }^{57}$.

57. Capmany. Memorias bistóricas..., vol. I-Marina, p. 7. 
Estas breves frases remiten a un apéndice del segundo volumen, en donde Capmany cita literalmente una serie de frases laudatorias de Barcelona, especialmente de personajes de los siglos XV, XVI y XVII -Alfonso el Magnánimo, Lorenzo Valla, Jeroni Pau, Lucio Marineo Sículo, Andrea Navagero, Gaspar Barreyros, Bernardino Gómez Miedes, Francisco Diago, Antonio Gallo, Giovanni Botero, Luis Núñez y Rodrigo Méndez de Silva-, sin excluir no obstante las referencias a los romanos Ausonio y Avieno y al carolingio Ermoldo el Negro, clásicas en la historiografía barcelonesa anterior, aunque poco pertinentes dado el mencionado recorte cronológico de su estudio ${ }^{58}$.

Una década más tarde, son aducidos de nuevo esos mismos testimonios, a los cuales se añaden las palabras de otros dos autores del Quinientos, Pedro Mexía y Miguel de Cervantes ${ }^{59}$. No obstante, esta recapitulación de elogios literarios conduce en el Suplemento a una estimación del uso y abuso moderno de aquella materialidad urbana tan alabada y tan pulcra, sometida a la presión de un comercio en auge constante, de la introducción de los coches en las calles, del vecindario en aumento y de la aparición de las grandes fábricas:

Por estas causas, sus calles, generalmente angostas, desembarazadas entonces de tanto bullicio y tormento estrepitoso de carruages, y sus casas, no tan ahogadas con el actual gentío y estrechez de las habitaciones, la hacían un pueblo más alegre, despejado y limpio, y por consiguiente una vivienda más amena y sosegada ${ }^{60}$.

Son frases atinadas que reflejan no sólo el perenne compromiso de Capmany con la observación empírica, sino también una nostalgia poco detectable en el volumen de 1779 y que refluirá en las Qüestiones críticas de 1807 a la vista de ese apogeo material cuyas expectativas - pronto puestas en tela de juicio a raíz del colapso de la Monarquía Hispánica en 1808- pudieran haber compensado la pérdida de las bellezas medievales. En efecto, en 1792, el barcelonés añora

... el aspecto noble, pulido y magnífico de sus edificios y común caserío, del qual ha desaparecido la mayor parte en este siglo, sin perdonar sus cimientos; ya con la continua reedificación de casas arruinadas o maltratadas de resultas de los dos últimos sitios y bombardeos que padeció desde 1691 hasta 1714; ya con la demolición de treinta años a esta parte de gran número de las antiguas que habían quedado enteras, con el fin de levantarlas sobre una nueva planta y construcción aprovechada para encerrar en corto sitio un vecindario que crece de día en día y se refunde y reconcentra dentro de las mismas habitaciones, no permitiendo la fortificación militar y el recinto de sus soberbios muros ensanchar la población ${ }^{61}$.

58. CAPMANY. Memorias bistóricas..., vol. II-Apéndice, núm. XIII, Descripción de la planta y situación de Barcelona, vista y amenidad de su territorio, y otras cosas, sacada de varios pasages de algunos escritores y viageros antiguos, pp. 19-22.

59. Capmany. Memorias históricas..., vol. III, pp. 367-369.

60. Ibidem..., p. 369.

61. Ibidem..., pp. 369-370. 
Tras constatar ese proceso de degradación, debido a dos procesos iniciados sucesivamente en el siglo XVIII y ambos relacionados a la vez con la vitalidad urbana y con la condición de Barcelona como plaza de guerra, Capmany subraya la tensión creciente entre las determinaciones estratégicas y el auge económico, mediante expresiones que se convertirán en la piedra fundacional de las campañas en pro de la demolición de las murallas y el ensanche ilimitado que habían de dar sus frutos seis décadas más tarde, entre 1854 y 1860, de la mano del ingeniero civil Ildefonso Cerdà ${ }^{62}$ :

Así es que, como los antiguos huertos y espaciosos patios se van reduciendo, sobre la estrechez de sus calles, esta ciudad, extendiendo hacia lo alto lo que había de ensanchar sobre su piso, ha venido a hacerse una como piña de casas, torres, cimborrios, miradores y azoteas que forman sin embargo una vista hermosísima y un objeto que sorprehende contemplado desde una altura o desde una proporcionada distancia.

Esta apreciación del efecto estético de la ciudad emergente tomada en su conjunto y a distancia es, sin duda, sincera, pero la ironía latente aflora pocos párrafos después por los atentos comentarios de detalle que le merecen las construcciones civiles de la época gótica que iban desapareciendo:

Los que vieron esta ciudad cien años atrás apenas la conocerían hoy, según las renovaciones, reparaciones y mudanzas que ha experimentado su caserío, entonces todo labrado de sillería, de estilo uniforme y de aspecto tan serio y elegante como el que se conserva aún en sus antiguos templos. Los que sepan examinar aquellas casas con ojos arquitectónicos, habrán de confesar que su forma y artificio guardan cierto ayre de suntuosidad y nobleza en la estructura de sus ventanas, portadas, zaguanes, pórticos y terrados cubiertos, la mayor parte adornados de colunas, graciosas labores, altos relieves de medallones, festones y otros caprichos del gusto antiguo, unido todo esto a la firmeza de la fábrica de cantería.

La consideración analítica de los elementos decorativos y estructurales de las antiguas mansiones barcelonesas sugiere a Capmany la posibilidad de una historia inductiva de la arquitectura que, sin embargo, él no desarrollará:

Así es que subsisten todavía casas y otros edificios públicos, de doscientos hasta quinientos años que, con respeto a su distinto estilo y estructura en los arcos, colunas, ventanage, remates, frisos y otras partes de la obra, pueden servir de monumentos cronológicos para la historia de la arquitectura civil, pues que en su artificio y ornatos se reconocen las variaciones del gusto que dominaba en diversas épocas ${ }^{63}$.

62. GraU, Ramon. "Inventores de la modernidad: Capmany y Cerdà en Barcelona». En GrAU, Ramon y MuÑoz, Josep M. (dirs.). Cataluña, una historia europea. Barcelona: Generalitat de Catalunya, 2006, pp. 86-95.

63. Capmany. Memorias bistóricas..., vol. III, pp. 370-371. 


\subsection{El reto del academicismo}

No es preciso recordar que el movimiento académico en la Europa de la Edad Moderna había hallado en Vitrubio y en sus editores y glosadores renacentistas el instrumento idóneo para que sus miembros ejerciesen las funciones corporativas de críticos de las obras existentes y, sobre todo, de árbitros y supervisores de las nuevas construcciones, ni que estas funciones de las academias auspiciadas por las casas reales fueron una parte del diseño de poder de la monarquía absoluta: la unificación estilística en nombre de los cánones de belleza universales sería expresión de la potencia y la unidad del Estado.

En 1772, Antonio Ponz, colaborador de Campomanes en la Academia de San Fernando, inició la publicación de los dieciocho volúmenes de cartas eruditas tituladas Viage de España, resultado de sus campañas haciendo balance del patrimonio artístico español, que la muerte interrumpió en 1792. En aquel primer volumen cuajan ya, a propósito de la catedral de Toledo, unos juicios sobre las prácticas gótica y barroca que no iban a variar sustancialmente en las visitas posteriores y que serán de aplicación al caso de Barcelona en 1788.

Con respecto a la arquitectura medieval, Ponz se separa de la antipatía e incomprensión manifestadas por Antonio Rafael Mengs, primera autoridad académica en Madrid, y se acerca al criterio moderado de Diego de Villanueva, seguidor a su vez de los críticos franceses de inicios del Setecientos, como Frémin y Cordemoy. Estos expertos en construcción racional y firmes partidarios del clasicismo contraponían, no obstante, la ligereza, economía y durabilidad de las iglesias góticas a algunos pesados templos, más costosos y a menudo de estabilidad precaria, posteriores a la reintroducción de los órdenes en la arquitectura europea ${ }^{64}$.

El juicio del académico valenciano sobre la fábrica original del templo toledano parece, en principio, muy favorable, aunque bajo la inevitable sombra que proyecta el culto a los órdenes grecorromanos:

La arquitectura de este templo es la que comúnmente llamamos gótica, en la qual he tenido siempre mucho que admirar, considerando su buena proporción, su firmeza, lo gentil de sus miembros y sus adornos, con ser todo tan diverso de los principios con que en Grecia e Italia se encontraron y perfeccionaron los órdenes de arquitectura conocidos ${ }^{65}$.

64. Sobre estos antecedentes: Grau, Ramon y LóPEz, Marina. «Origen de la revaloració del gòtic a Barcelona: Capmany, 1792». En Cubeles, Albert y Grau, Ramon (coords.). El procés urbà i la identitat gòtica de Barcelona. Barcelona: Ajuntament de Barcelona, 2003, Barcelona Quaderns d'Història, 9, pp. 144-153.

65. [PONZ, Antonio] «Pedro Antonio de la Puente». Viage de España, o Cartas en que se da noticia de las cosas más apreciables y dignas de saberse que hay en ella. Madrid: Joachín Ibarra, 1772, vol. I, p. 36. 
Por lo que respecta a la más famosa intrusión del barroco en esa catedral, el Transparente, la crítica de Ponz, feroz e inapelable, conduce a la proposición de un vasto plan de intervención de la Academia a través de sus autorizados "profesores» y costeada por las mismas instituciones locales afectadas:

Aunque no fuera sino para evitar semejantes desaciertos, sería muy propio de las santas iglesias tener asalariados hábiles profesores que, estableciendo el buen gusto, desterrasen el pésimo, que infelizmente ha denigrado de muchos años a esta parte tan magníficos templos ${ }^{66}$.

El tomo decimocuarto del Viage de España se inicia con un halagador -o tal vez sólo cauto- reconocimiento de la excepcionalidad de Cataluña, muy acorde con el criterio del Campomanes más experimentado:

Como el objeto de esta obra es estimular por todos caminos el progreso en materia de las nobles artes y en todos los objetos que desde el principio se propuso, usa el autor en estas cartas del mismo lenguaje que en todas las demás anteriores, aunque cree que sobre ciertos puntos de aplicación e industria no necesita el Principado de Cataluña de las exhortaciones que en otras provincias de España pueden ser útiles para acertar con los medios de su prosperidad y aumento ${ }^{67}$.

Poco después, se esgrimen los logros barceloneses como argumento en la sempiterna polémica promovida por los enciclopedistas sobre el atraso de España:

Es, pues, Barcelona la ciudad de España que más desmiente las imputaciones de algunos escritores extrangeros, empeñados en divulgar nuestra desidia, abandono, pereza, falta de industria y otras gracias con que nos favorecen; y lo mismo puede decirse de la mayor parte del Principado ${ }^{68}$.

El triunfo de las tesis sostenidas por Capmany en la parte de las Memorias históricas publicada hasta el momento, cuya lectura recomienda Ponz ahí mismo, se antoja completo; pero se ve paliado inmediatamente por una devaluación práctica del recurso a la historia -sin distinguir entre las apologías tradicionales y el nuevo conocimiento crítico-, en una consideración orientada a un futuro que, al parecer, no tendría por qué guardar relación con el pasado:

Dexemos nosotros por ahora de detenernos en lo que fuimos, pues tantos lo han dicho, para hablar de lo que somos y podemos ser, reduciendo nuestras relaciones al estado presente, que es el que nos importa y conviene mejorar, hablando siempre con la imparcialidad y libertad acostumbrada en los asuntos tratados hasta ahora.

Bueno y muy laudable es acordar las acciones de nuestros pasados, especialmente si fueron mejores que nosotros, y aquéllas más útiles e importantes que las nuestras;

66. Ibidem, p. 64, nota.

67. POnZ. Viage de España, vol. XIV (1788), pp. XV-XVI.

68. Ponz. Viage de España, vol. XIV, p. 6. 
pero el proponer, exhortar y conseguir que nosotros seamos mejores que ellos, hoc opus, bic labor. El reynado del gran Carlos Tercero, padre amantísimo de sus fieles vasallos, desmontando insuperables estorbos, ha abierto y abre ancho camino para llegar a conseguir tanta dicha ${ }^{69}$.

Al ocuparse de los templos góticos de Barcelona, y en primer lugar de su catedral y de Santa María del Mar, reaparecen tanto el breve y frío reconocimiento del mérito de las estructuras góticas como las enérgicas y prolijas condenas de los añadidos barrocos, especialmente acerbas a propósito del templo parroquial, por topar en este caso con un altar mayor de muy reciente factura, inaugurado en 1782 y fruto de maestros gremiales:

Para guardar un cierto orden en el examen metódico de los templos debiera hablarle a V. ahora de otro también de la arquitectura que llaman gótica, gentil en su género y bien fabricado quanto puede darse, con treinta y ocho capillas, algunas de las quales sirven de ingreso, y tres altas naves; pero no quisiera haber entrado en él por no haber visto uno de los mayores y más costosos desatinos que se han hecho en nuestra dichosa edad ${ }^{70}$.

La larga diatriba que sigue conduce a una imputación de responsabilidades a los dirigentes locales, que, según Ponz, debieran haberse impuesto al mal gusto de los feligreses, por mucho que éstos hubiesen costeado esa grosera imitación del célebre baldaquín de Bernini. Y para el académico valenciano este control importaba especialmente en una ciudad rica como la capital catalana, que, junto con Cádiz, era punto principal de acceso a España y donde, por tanto, los extranjeros adquirían las primeras ideas sobre el país:

Barcelona y Cádiz, ciudades ambas de las más opulentas y principales del reyno, y las más freqüentadas por su situación y por el comercio de los forasteros, son como las piedras de toque para que éstos vengan en conocimiento de lo que podrá haber dentro de él en materia de buen gusto y conocimiento artístico; pero desgraciadamente parece que se ha puesto cuidado en hacer que lo formen muy malo, a costa de grandes caudales, gastados en ellas sin elección ni acierto ${ }^{71}$.

Un par de años antes, en el «Discurso preliminar» del Teatro bistórico-crítico de la eloqüencia española, Capmany había trazado la evolución de la prosa literaria castellana buscando la autenticidad en la expresión antes que la brillantez o la elegancia. En los mejores textos del amanecer bajomedieval, aprecia «una amable sencillez que, a pesar de acompañarla alguna vez cierta especie de rusticidad, es muy eficaz para exprimir toda la verdad de los sentimientos naturales». En contraste, ha de lamentar la decadencia del siglo XVII, cuando, por un "general contagio",

69. Ponz. Viage de España, vol. XIV, pp. 4-5.

70. PONZ. Viage de España, vol. XIV, pp. 15-16.

71. Ponz. Viage de España, vol. XIV, pp. 17-18. 
los escritores abandonaron la perfección clásica conseguida en tiempo de Felipe II y se empeñaron en seducir a sus lectores con artificios variados, de gusto dudoso. Estos recursos barrocos le parecían repugnantes desde el punto de vista de una época nueva, «en que se prefiere que las ideas campeen sueltas, que se sucedan la una a la otra rápidamente, que la frase tenga más precisión, desembarazada de aquel vano luxo de sentencias e inútil acompañamiento de palabras, y que el pensamiento se introduzca en el estilo con toda su viveza y calor como se concibe en el alma» ${ }^{72}$.

En lo que se refiere al estilo barroco y a sus modalidades populares en arquitectura y artes plásticas, es, pues, más que probable que Capmany compartiese el negativo criterio que acababa de leer en el Viage de España a propósito del altar mayor de Santa María del Mar. Su defensa integral de las corporaciones artesanas tenía, efectivamente, su talón de Aquiles en las incursiones de los agremiados en la esfera de las nobles artes, legitimada por la tradición pero ya no por sus resultados. Así pues, no podía oponerse de manera frontal al criterio expresado por Ponz, aunque éste desembocase inequívocamente en una severa tutela de la Academia de San Fernando sobre las actividades artísticas barcelonesas, poco deseable desde el punto de vista local.

En tales condiciones, el autor catalán no pudo sino articular una defensa oblicua del arte barcelonés, centrada en los ejemplares conservados de la arquitectura gótica y que aflora como una coronación coherente -y sin embargo poco previsible- de la apología del sistema económico, social y político de la ciudad medieval que, como hemos visto arriba, era el objetivo de las Memorias históricas:

Después de haber examinado a Barcelona por el lado de las artes útiles y oficios manuales, en que han sido esmerados sus activos hijos, justo será contemplarla por el de las nobles artes, principalmente la arquitectura, en la qual no sobresalieron menos la habilidad y el primor de sus artífices que el espíritu y la magnificencia de sus ciudadanos ${ }^{73}$.

\subsection{La belleza especial de la arquitectura gótica}

El análisis de la arquitectura gótica en el Suplemento se abre con una oración concesiva dirigida al "viagero curioso», es decir, Antonio Ponz, quien en su reseña barcelonesa había exaltado por encima de cualquier otro edificio la fachada renacentista del palacio de la Diputación del General:

Aunque no puede Barcelona, como otras ciudades de Europa, presentar a los ojos del viagero curioso edificios magníficos de la elegante arquitectura griega desde su

72. Capmany y de Montpalau, Antonio de. Teatro bistórico-crítico de la eloqüencia española. Madrid: Antonio de Sancha, 1786, vol. I, pp. XXXII y XLIV.

73. CAPMANY. Memorias históricas..., vol. III, p. 367 
restauración o renacimiento en Occidente fuera de la parte anterior de la Casa de la Diputación, a lo menos, en el carácter atrevido, delicado y grandioso del orden que llamamos vulgarmente gótico, que nació en el siglo XIII y acabó a principios del XVI, las obras que aún conserva pueden competir con las de otro pueblo de dentro y fuera de España, principalmente las consagradas al culto divino ${ }^{74}$.

Es un rasgo típico de la habilidad retórica de Capmany que, precisamente en esa concesión inicial al criterio del oponente, sea deslizada la idea de que va a considerar la denostada arquitectura gótica como un "orden"; es decir, como un estilo con normas específicas. Sólo en la cultura británica de la segunda mitad del siglo XVIII podríamos hallar alguna expresión rotunda de tal tesis y, sobre todo, de sus implicaciones críticas:

When an architect examines a Gothic structure by Grecian rules, he finds nothing but deformity. But the Gothic architecture has its own rules, by which when it comes to be examined, it is seen to have its merit, as well as the Grecian. The question is not, which of the two is conducted in the simplest or truest taste, but, whether there be not sense and design in both, when scrutinized by the laws on which each is projected $^{75}$.

En la reseña de las iglesias medievales de Barcelona, regida por esa consideración del gótico como un estilo con reglas propias, Capmany sigue el mismo orden que Ponz, destacando primero la catedral y, a continuación, Santa María del Mar; lo cual no tiene nada de particular, dada la prominencia de esos dos edificios dentro de la trama y el perfil de la ciudad. Pero, a diferencia del autor del Viage de España, que utiliza formulariamente el marchamo de "gótico" para dar al lector una idea rápida sobre la época de construcción y sobre la mediocre calidad esperable de los edificios que va comentando, aquí encontramos lecturas individualizadas, basadas en la experiencia sensorial y tendentes a destacar la excelencia de los edificios. En la catedral, subraya «la elegancia y la harmonía más sabia de las proporciones», y en el templo parroquial, «un plan más atrevido, más ligero y más gallardo que el de la catedral en cuya execución compiten la gentileza gótica con la ingeniosa y feliz ciencia del arquitecto». La comparación entre los dos ejemplares barceloneses desemboca en una suspensión del juicio, satisfactoria, quizás no para el inquieto "viagero curioso", pero sí para el «espectador inteligente»:

... de suerte que en ambos templos, diferentes en la estructura, dimensiones y distribución de las partes, siendo una misma la forma y estilo arquitectónico, no acierta el espectador inteligente a quál dar la preferencia, porque, si en el primero halla más en que contentarse la razón, en el segundo la imaginación tiene más en que cebarse.

74. Ibidem, pp. 371-372. En: GRAU y LÓPEZ. "Origen de la revaloració...", pp. 160-168, puede hallarse un análisis más detallado del discurso de Capmany, que ocupa las pp. 372-377 de ese volumen. En lo sucesivo, no detallaremos en nota la procedencia exacta de los extractos sacados de esas páginas.

75. [HuRD, Richard]. Letters on Chivalry and Romance. Londres: Millar, 1762, p. 62. 
En fin, son fábricas que deben juzgarse, no por las descripciones y relaciones, sino por la vista; esto es, por los efectos que dexan en el ánimo del espectador.

Tras esta ecléctica apelación tanto a la «razón» -es decir, al fundamento del dogma clásico- como a la "imaginación" -esto es, a la raíz de una consideración subjetiva de la belleza-, inequívocamente enmendada por la afirmación de la primacía de la visión directa, una acotación en el margen de la página, "Reflexiones sobre la arquitectura gótica», marca el tránsito hacia una generalización que ha sorprendido a los lectores ochocentistas y novecentistas de Capmany -a quien se suponía poco o nada versado en materia de arte- por su precoz marcha hacia el romanticismo ${ }^{76}$. Sobre su familiaridad con la crítica estética, baste decir que, ya en 1781, Jovellanos mencionaba haber leído la Historia del arte entre los antiguos de Winckelmann en una traducción de Capmany, manuscrito que obraba en manos de Campomanes ${ }^{77}$. Por otro lado, dentro de la cultura setecentista, la retórica aún figuraba frecuentemente como una de las artes liberales, junto a la pintura, la escultura, la arquitectura y la música, y Capmany había publicado en 1777 un tratado sobre esa materia, la Filosofía de la eloqüencia. Ahí, donde las analogías entre la literatura y las otras artes están al orden del día, se atestigua la apertura del autor a las diversas corrientes estéticas filtradas por la muy plural Encyclopédie de Diderot y D'Alembert.

En efecto, en las páginas del célebre diccionario se publicó un artículo póstumo e inacabado de Montesquieu sobre el gusto, donde este autor, tan admirado por Capmany, seguía los cauces tradicionales del academicismo francés y, al confrontar el estilo gótico con el clásico, se mostraba, más que refractario, incapaz de desentrañar el arte medieval:

L'architecture gothique paroît très variée, mais la confusion des ornemens fatigue par leur petitesse; ce qui fait qu'il n'y en a aucun que nous puissions distinguer d'un autre, et leur nombre fait qu'il n'y en a aucun sur lequel l'oeil puisse s'arrêter; de manière qu'elle déplaît par les endroits même qu'on a choisis pour la rendre agréable. Un bâtiment d'ordre gothique est une espèce d'énigme pour l'oeil qui le voit, et l'âme est embarrassée, comme quand on lui présente un poëme obscur. L'architecture grecque, au contraire, paroît uniforme, mais comme elle a les divisions qu'il faut et autant qu'il en faut pour que l'âme voye précisément ce qu'elle peut voir sans se fatiguer, mais qu'elle en voye assez pour s'occuper, elle a cette variété qui fait regarder avec plaisir ${ }^{78}$.

76. Sobre estas reseñas: Grau y LóPEz. "Origen de la revaloració...”, pp. 169-170.

77. Jovellanos, Gaspar Melchor de. "Oración [Elogio de las Bellas Artes]». En Distribución de los premios concedidos por el rey nuestro señor a los discípulos de las nobles artes hecha por la Real Academia de San Fernando en la junta pública de 14 de julio de 1781. Madrid: Joachín Ibarra, 1781, p. 50, nota.

78. Montesquieu, Charles-Louis Sécondat, barón de. "Essai sur le goût dans les choses de la nature et de l'art». En Encyclopédie ou Dictionnaire raisonné des sciences, des arts et des métiers. Paris, 1757, vol. 7, pp. 763-764. 
Siguiendo dócilmente al maestro gascón, y en concordancia, por tanto, con la ortodoxia, el autor barcelonés inserta en su Filosofía de la eloqüencia esta única y desfavorable mención de la arquitectura gótica:

Hay estilos que parecen variados, y no lo son; y otros que lo son y no lo parecen. El estilo matizado de florecitas y sentencillas, bordado de menudas sutilezas, de énfasis y antíthesis imperceptibles embaraza al alma por su oscuridad y confusión; así como un edificio de orden gótico, por la variedad y enredo de sus laborcitas y pequeñez de sus adornos es una fatiga para la atención, y para la vista un enigma.

Al contrario, el estilo tegido de frases claras, períodos llenos, términos nobles y sencillos, magníficas transiciones y pensamientos grandes deleyta a las personas de todos los siglos y países. Este estylo, por no salir de la misma comparación, es como la arquitectura griega, que parece uniforme y tiene las divisiones necesarias para ver precisamente todo lo que podemos sin fatigarnos, y lo que basta para tenernos ocupados $^{79}$.

Pero en las mismas páginas, se hace eco de otros artículos de la Encyclopédie impregnados de elementos de la nueva estética sensualista, como el de Voltaire sobre la imaginación, que le dicta la definición de este concepto, fundamental, como hemos visto, en su aproximación visual a los templos góticos. Voltaire, a su vez, se había inspirado en The pleasures of the imagination, los innovadores ensayos publicados en tiempo de la Guerra de Sucesión española por Joseph Addison y que abrían nuevas oportunidades de hallar belleza artística fuera de la tradición clásica ${ }^{80}$.

Pocos años después, en 1725, el gran poeta Alexander Pope, en el prólogo a su edición de Shakespeare, comparaba el estilo dramático de este escritor, nada respetuoso con las famosas tres unidades, con la arquitectura gótica, también heterodoxa, menos elegante y brillante que la clásica pero más fuerte y solemne, más variada y, en conjunto, capaz de inspirar más veneración ${ }^{81}$. Es, en efecto, en la cultura británica del Setecientos donde hallaremos con más frecuencia puntos de vista semejantes a los que va a expresar Capmany, por ejemplo, en el nítido arranque de sus reflexiones:

Por lo general es más sensible la impresión que causa el aspecto de las fábricas góticas que el de las obras modernas.

Idéntica subversión del juicio académico podemos leer en un texto que Horace Walpole publicó por vez primera en 1762:

79. Capmany, Antonio de. Filosofía de la eloqüencia. Madrid: Antonio de Sancha, 1777, p. 75.

80. ÉTIENVRE. Réthorique et patrie..., pp. 154-156, además de documentar la deuda de Capmany con Voltaire, aventura que tal vez leyó también directamente a Addison.

81. Pope, Alexander. «Preface». En The Works of Shakespeare. Londres, 1747, vol. I, pp. XLV-XLVI. 
It is difficult for the noblest Grecian temple to convey half so many impressions to the mind, as a cathedral does of the best Gothic taste ${ }^{82}$.

En la exploración de las propiedades de las iglesias góticas, Capmany admite que sus proporciones y ornamentación sorprenden al espectador, pero eso no da lugar a ninguna reserva o a la acostumbrada condena, sino a una afirmación de sus buenos efectos, siguiendo líneas que sugieren el conocimiento de las teorías de Edmund Burke acerca de la belleza y la sublimidad y de los elementos que conducen a entrar en este segundo ámbito de impresiones estéticas, especialmente intensas, en particular el concepto de infinito artificial:

There are scarce any things which can become the objects of our senses that are really and in their own nature infinite. But the eye not being able to perceive the bounds of many things, they seem to be infinite, and they produce the same effects as if they were really $\mathrm{so}^{83}$.

Lejos de ser engaño reprobable, la ilusión creada por los artífices es para Burke un requisito de la sublimidad:

A true artist should put a generous deceit on the spectators, and effect the noblest designs by easy methods. Designs that are vast only by their dimensions are always the sign of a common and low imagination. No work of art can be great but as it deceives $^{84}$.

A propósito de la característica verticalidad del gótico, el barcelonés afirma:

Nadie ignora que de dos salas de iguales espacios, la que tenga el techo más elevado parecerá mayor que la otra; así es que todos los templos góticos tienen siempre un ayre de grandiosidad, aun quando no sean realmente grandes.

Y rectificando su anterior acuerdo con Montesquieu, justifica ahora la minuciosidad de la composición estructural y decorativa por sus resultados en el momento de la percepción visual:

... todo lo qual da una ilusión de espaciosidad que no existe realmente en el área del edificio, porque las formas y pequeñez de las partes causa a la vista el mismo efecto que la realidad de las distancias, que achican los objetos grandes en su lugar respectivo.

Establecido el mérito de las antiguas iglesias góticas por sus efectos sobre el sentido de la vista, que se reconocen implícitamente como producto deliberado de

82. Walpole, Horace. Anecdotes of Painting in England. Londres: Dodsley, 1782, 3. ${ }^{a}$ ed., vol. I, p. 182

83. BuRKE, Edmund. A Philosophical Enquiry into the Origin of our Ideas of the Sublime and Beautiful. Londres: Dodsley, 1757, pp. 52-53.

84. Ibidem, pp. 58-59. 
los cultivadores de ese estilo, Capmany aborda sus efectos psicológicos mediatos, primero en relación con la conciencia histórica y luego con el sentimiento religioso.

Sostiene el comentarista en primer lugar que la reintroducción de la arquitectura grecorromana, "la que se estila en los edificios que vemos erigirse a nuestros ojos", ha abolido su capacidad de sugestión histórica, mientras que el gótico la conserva, precisamente porque "ha perdido ya su uso cerca de tres siglos ha". En conclusión, "quanto más se aparta aquel género de arquitectura del actual, me da una idea más cabal de la distancia del tiempo y mayores auxilios para la comparación». Aunque negada al «vulgo, quien no puede medir la duración ni la serie de los siglos, por ignorar los sucesos que en ellos han ocurrido", en esta experiencia "mi imaginación recorre, sin poderla detener, la historia y las vicisitudes acaecidas cronológicamente en este intervalo, o por siglos, o por épocas o por reynados, y contempla sus paredes como testigos de vista de generaciones que pasaron".

No es preciso insistir mucho en la siguiente línea de reflexión, por cuanto adopta la tesis sobre la especial adecuación del estilo gótico a la función religiosa, puesta en circulación por los racionalistas franceses de principios del siglo XVIII y ya bien implantada en todos los ámbitos en aquel momento final de la centuria, aunque el enunciado particular de Capmany trasluce un tipo de aproximación a la religión cristiana que el romanticismo desarrollará:

Por otra parte la arquitectura gótica imprime cierto género de tristeza deliciosa que recoge el ánimo a la contemplación, y así parece la más propia para la seriedad augusta de los templos.

\subsection{La recuperación del gótico para la ciudad moderna}

En su Essai sur l'architecture de 1753, Marc-Antoine Laugier no había querido dejar de transmitir sus impresiones sensoriales al entrar en Notre-Dame de Paris, aunque entrasen en conflicto con los dogmas clásicos:

... au premier coup d'oeil mes regards sont arrêtés, mon imagination est frappée par l'étendue, la hauteur, le dégagement de cette vaste nef; je suis forcé de donner quelques momens à la surprise qu'excite dans moi le majestueux de l'ensemble. Revenu de cette première admiration, si je m'attache au détail, je trouve des absurdités sans nombre: mais j'en rejette le blâme sur le malheur des temps. De sorte qu'après avoir bien épluché, bien critiqué, revenu au milieu de cette nef, j'admire encore, et il reste dans moi une impression qui me fait dire: Voilà bien des défauts, mais voilà qui est grand ${ }^{85}$.

En sus Observations sur l'architecture de 1765, el mismo autor hacía sus recomendaciones sobre cómo intervenir en las iglesias de aquel género, para sacar de

85. [Laugier, Marc-Antoine]. Essai sur l'architecture. Paris: Duchesne, 1753, pp. 201-202. 
ellas el mejor partido posible, con el propósito de «donner aux massifs, s'il le peut, une forme plus simple, plus naturelle et plus coulante», mediante la eliminación de ornamentos considerados superfluos o con el enmascaramiento de los soportes, viendo "si en retranchant ou en ajoutant quelque chose on peut les arrondir jusqu'à leur donner une forme qui imite celle des colonnes» ${ }^{86}$.

Quizás no tan extremas, pero de espíritu semejante son las recomendaciones de Antonio Ponz en España. A propósito de la catedral de León, dice en 1783:

Quando todas estas antiguas iglesias, acabadas de edificar, tenían conformidad en sus altares y demás ornamentos, precisamente aquella unidad de estilo había de agradar. No sería bueno, con todo eso, habiendo ahora de hacer retablos, órganos, coros y cosas semejantes dentro de ellas, imitar al estilo gótico, sino el de la arquitectura greco-romana, que, como mejor y más grandiosa, no solamente no las ofende, sino que les da mayor carácter de magestad, porque, si se hiciera de otro modo, sería perpetuar el estilo gótico y no conseguir la perfecta restauración de las artes ${ }^{87}$.

A partir de la década de 1770, especialmente, en las principales iglesias de Barcelona se habían producido intervenciones impulsadas a la vez -pero no siempre con objetivos coincidentes- por una sociedad urbana que quería expresar su enriquecimiento en obras piadosas, por un reformismo episcopal tendente a subrayar la condición de los templos parroquiales como lugares de culto abiertos a toda la comunidad laica y por las nuevas directrices académicas. En Santa María del Mar, los trabajos fueron especialmente ambiciosos y facilitaron el redescubrimiento del valor genuino de la concepción gótica de su espacio. Del siglo XVII databa un inacabado retablo mayor que se quiso substituir en 1769 , dentro de una reordenación del presbiterio, mediante un concurso público, entre cuyas propuestas el obispo y un destacado ingeniero militar de la plaza eligieron el proyecto que tanto había de disgustar a Antonio Ponz. Más allá del acierto o desacierto del baldaquín, es de notar que la nueva disposición absidal abierta y el traslado del coro desde el centro de la nave hasta el entorno del nuevo altar mayor encajaban con las recomendaciones de Laugier para las catedrales francesas y de la Academia de San Fernando para las españolas $^{88}$.

Ante esta y otras intervenciones recientes en los templos barceloneses, Capmany distingue entre aquellas que ignoran las características propias de los edificios, condenadas con energía, y las que tienden a restituir su aspecto original, dignas de alabanza. Sin duda, en aquel tiempo estos juicios favorables eran facilitados por la tendencia a la unificación del espacio interior peculiar de la modalidad catalana o meridional del estilo gótico, que garantizaba resultados digeribles incluso desde el punto de vista neoclásico.

86. LAUGIER, [Marc-Antoine]. Observations sur l'architecture. La Haya, 1765, pp. 135-138.

87. POnZ. Viage de España, vol. XI (1783), p. 208.

88. Más detalles en: Grau y LóPEz. "Origen de la revaloració...”, pp. 166-167. 
Capmany sostiene que las iglesias, "para que no se pierda el aspecto de antigüedad que las hace tan venerables, deben conservar la tez morena de su sillería en su primitivo estado». Siendo además mérito principal de estas obras «la prolixa y artística simetría, corte y colocación de sus sillares", se pronuncia con mucha gracia contra «los rebocos de yeso, de pintura o el enjalbegado de cal, indiscreta práctica que se ha introducido en Barcelona", concretamente en la iglesia del Pino, "Convirtiendo los templos antiguos en almacenes nuevos, que tales parecen los enjalbegados». Contra el pretexto aducido por los promotores de estas prácticas, que justificaban el blanqueo de los muros para dar más luz a las iglesias, argumenta que toda la claridad deseable se puede obtener mediante el retorno a la disposición original de los ventanales:

Quando los quieran más alumbrados, abran las muchas claraboyas que la mezquindad de los modernos, por no gastar en vidrieras, tiene tabicadas, en manifiesto agravio del buen gusto del artífice y de la decoración de la fábrica.

E incita ciertamente a reponerlas, en lo que parece un precoz anuncio de las prácticas neogóticas que habían de imponerse desde mediados del siglo XIX y dejar su sello en el moderno arte catalán hasta entrado el siglo XX:

Fácil sería volverlo a ver si se repusieran las vidrieras de todas sus magníficas claraboyas con imaginería iluminada o con otros dibuxos del gusto gótico, por pedirlo así el orden de su arquitectura.

Sin embargo, en una nota al pie de esta misma frase, vemos que Capmany está aprovechando aquí la reforma de Santa María del Mar, en la que tal restauración de las vidrieras se ha puesto en práctica. Debemos interpretar el argumento que ahí despliega como el hábil y elocuente clímax de su tácita respuesta a la censura de Ponz. En efecto, los discutidos responsables de las obras parroquiales son elogiados, mientras que el juicio sobre el controvertido altar mayor es eludido, puesto que se deduce que, en cualquier caso, no impide el disfrute visual del gran espacio recuperado:

Esta restauración se ha verificado ya en el nobilísimo templo de Santa María del Mar por la discreción y generosidad de los obreros, quando se limpió y despojó del coro baxo, de altares postizos y otros adornos que le embarazaban, restituyéndole a la hermosura y sencillez de su primitiva forma. El que hubiese visto este templo antes del año 1779 y le vea ahora, acabará de convencerse de que las ventanas, tan magníficas y profusamente repartidas en aquella fábrica gótica, son unos claros esenciales para la simetría y proporción de todas sus partes, y el principal requisito de su belleza y armonía. A no haber tenido las claraboyas este destino en la traza de la obra, no las hubiera rasgado el artífice hasta las cornisas, haciendo juego con los elevados arcos de las capillas, que también entraban en el plan del edificio en esta y en otras iglesias. 
Para acabar, no estará de más añadir una información colateral que evite la impresión de que Capmany fuese un pensador aislado o un profeta que clamaba en el desierto. Al inicio de la década de 1770, mientras con acierto desigual se remozaban las iglesias, la Junta Particular de Comercio de Barcelona, que pronto se convertiría en patrocinadora de las Memorias históricas de nuestro autor, encargaba un proyecto para reedificar su sede en el antiguo edificio del Consulado, con la condición de que «en la disposición de dicho proyecto se huviese respeto al grande salón, a fin de dejar a la posteridad memoria de la magnificencia del antiguo edificio de la Casa Lonja». En 1785, el autor de ese proyecto y director de la obra, que daría como resultado el mejor edificio de la Barcelona dieciochesca en clave neoclásica, Juan Soler y Faneca, intentaba añadir argumentos artísticos al fundamento historicista de la decisión conservadora de los comerciantes e insistía en el parentesco tipológico del salón de contrataciones con las antiguas basílicas romanas, ya que no podía aprobar su decoración escultórica, producto del "gotismo, enemigo de la verdadera arquitectura griega romana ${ }^{89}$. Por su parte, en 1792, Capmany, tras citar el salón del Palacio Real Menor y el Salón de Ciento de la Casa de la Ciudad como otros interiores destacados dentro del gótico civil barcelonés, subrayaba que «sobre todos se aventaja por la magnificencia y gallardía el Salón de la Lonja del Mar».

\section{EPÍlogo}

En la obra de Antonio de Capmany la adhesión emocional al patrimonio histórico fue la otra cara de su espíritu crítico, base de su gran tarea de construcción y depuración del conocimiento sobre la sociedad. Todo lo que de él hemos leído en páginas precedentes pertenece a la época de la Ilustración, a un ambiente cultural relativamente tranquilo o ecléctico, tal vez aquella "España posible» de que hablaba Julián Marías, donde se podía mantener el equilibrio entre impulsos a la larga divergentes. Justo en el momento de publicación de los dos volúmenes del Suplemento a las Memorias históricas, ese ambiente intelectual empezaba a quebrarse sacudido por la Revolución francesa. Pero el Capmany crítico, escéptico incluso, se mantiene todavía en las Qüestiones críticas de 1807. El gran giro histórico se había de producir en España al año siguiente, con la invasión napoleónica y el colapso del poder borbónico. El historiador barcelonés, que se sentía ya un anciano, con sus sesenta y cinco años a cuestas, experimentó entonces una de esas transformaciones psicológicas que Tolstoi ha sabido narrar con su arte inigualable. Por de pronto, en 1808 triunfó con el célebre panfleto Centinela contra franceses, que el mismo Napoleón quiso leer y donde, ya libre de la hipoteca borbónica, Capmany

89. [SOLER Y FANECA, Juan]. Dicertación del antiguo edificio de la Casa Lonja y noticia de lo que ha ocurrido durante la construcción de las obras... En MOLINÉ Y BRASÉs, Ernest. Les Costums marítimes de Barcelona universalment conegudes per Llibre del Consolat de Mar. Barcelona: Henrich, 1914, p. 362. 
asocia el nuevo cesarismo con el absolutismo de Felipe V, como dos infaustas importaciones procedentes de Francia, y donde teoriza a España como una nación de naciones que, precisamente gracias a sus fuertes personalidades regionales, ha sido capaz de reaccionar cuando el centro del poder ha sucumbido. Luego, en sus trabajos para la convocatoria y organización de las Cortes de Cádiz, y más tarde todavía en el desarrollo de las sesiones parlamentarias, Capmany intentó insuflar en la naciente Constitución española el espíritu de las antiguas constituciones de los reinos de la Corona de Aragón, llevando su bien fundamentado historicismo más allá de lo que resultaba aceptable o parecía operativo a sus colegas liberales, especialmente a los procedentes de las provincias de la Corona de Castilla.

A diferencia del escaso éxito a corto plazo de su empeño político en el seno de las Cortes Constituyentes y de su incierta influencia posterior en la concepción de España, el Antonio de Capmany admirador de la cultura europea renovada, el defensor del espíritu menestral y de la economía productiva, el cantor de las libertades municipales, el crítico de la densificación urbana, el apologista del arte gótico; en suma, el Capmany fiel al racionalismo empírico, ha sido el principal moldeador de la imagen que los barceloneses tienen de su comunidad. Sus efectos son perceptibles todavía hoy.

\section{BIBLIOGRAFÍA}

\section{Fuentes}

\subsection{Obras de Antonio de Capmany y de Montpalau}

"Pedro FERNÁNDEZ». Comentario sobre el Doctor Festivo y Maestro de los Eruditos a la violeta, para desengaño de los españoles que leen poco y malo (Sevilla, 28 de enero de 1773). En Marías, Julián. La España posible en tiempo de Carlos III. Madrid: Sociedad de Estudios y Publicaciones, 1963, pp. 181-218.

"Ramon Miguel Palacio». Discurso económico-político en defensa del trabajo mecánico de los menestrales y de la influencia de sus gremios en las costumbres populares, conservación de las artes y honor de los artesanos. Madrid: Antonio de Sancha, 1778.

Filosofía de la eloqüencia. Madrid: Antonio de Sancha, 1777.

Memorias históricas sobre la marina, comercio y artes de la antigua ciudad de Barcelona. Madrid: Antonio de Sancha, 1779, 2 vols.

Teatro bistórico-crítico de la eloqüencia española. Madrid: Antonio de Sancha, 1786, vol. I. Discurso político-económico sobre la influencia de los gremios en el Estado, en las costumbres populares, en las artes y en los mismos artesanos. En Semanario erudito. Madrid: Blas Román, X (1788), pp. 173-224.

Código de las costumbres marítimas de Barcelona, hasta aquí vulgarmente llamadas Libro del Consulado. Madrid: Antonio de Sancha, 1791, 2 vols.

Suplemento a las Memorias históricas sobre la marina, comercio y artes de la antigua ciudad de Barcelona. Madrid: Imprenta de Sancha, 1792, 2 vols. 
ANTONIO DE CAPMANY Y LA CIUDAD DE BARCELONA: EL VALOR DE LO EMPÍRICO...

Qüestiones críticas sobre varios puntos de historia económica, política y militar. Madrid: Imprenta Real, 1807.

\subsection{Publicaciones anteriores}

Bodin, Jean. Les six livres de la République. Paris, 1578, 3. ${ }^{a}$ ed.

BufFon, Georges-Louis de Leclerc, conde de. Histoire naturelle, générale et particulière. Paris: Imprimerie Royale, 1760, vol. VIII.

[CAmpomanes, Pedro Rodríguez]. Discurso sobre el fomento de la industria popular. Madrid: Antonio de Sancha, 1774.

[ClicQuot De BleRVACHe, Simon]. Considérations sur le commerce, et en particulier sur les compagnies, sociétés et maîtrises. Ámsterdam, 1758.

D'Holbach, Paul Henri Thiry, barón]. Système de la nature, ou des loix du monde physique et du monde moral. Londres, 1770.

Diderot, Denis. «Homme (Politique)». En Encyclopédie ou Dictionnaire raisonné des sciences, des arts et des métiers. Paris, 1765, vol. 8, p. 278.

[HuRD, Richard]. Letters on Chivalry and Romance. Londres: Millar, 1762.

JovelLanos, Gaspar Melchor de. "Oración [Elogio de las Bellas Artes]». En Distribución de los premios concedidos por el rey nuestro señor a los discípulos de las nobles artes hecha por la Real Academia de San Fernando en la junta pública de 14 de julio de 1781. Madrid: Joaquín Ibarra, 1781, pp. 35-102.

[Laugier, Marc-Antoine]. Essai sur l'architecture. Paris: Duchesne, 1753.

LAUGIER, [Marc-Antoine]. Observations sur l'architecture. La Haya, 1765.

MaBly, Gabriel Bonnot, abbé de. Observations sur l'histoire de France (1765). En Oeuvres complètes, Londres. 1789.

Montesquieu, Charles-Louis Sécondat, barón de. L'Esprit des lois (1748). En Oeuvres complètes. Paris: Éditions du Seuil, 1964, pp. 527-795.

Montesquieu, Charles-Louis Sécondat, barón de. "Essai sur le goût dans les choses de la nature et de l'art». En Encyclopédie ou Dictionnaire raisonné des sciences, des arts et des métiers. Paris, 1757, vol. 7, pp. 762-767.

Muratori, Ludovico Antonio. Dissertazioni sopra le antichità italiane. Roma, 1755.

[POnZ, Antonio] «Pedro Antonio de la Puente». Viage de España, o Cartas en que se da noticia de las cosas más apreciables y dignas de saberse que hay en ella. Madrid: Joachín Ibarra, 1772, vol. I.

PONZ, Antonio. Viage de España, en que se da noticia de las cosas más apreciables y dignas de saberse que hay en ella. Madrid: Ibarra, 1777-1794, vv. II-XVIII.

Pope, Alexander. "Preface». En The Works of Shakespeare. Londres, 1747, vol. I, pp. XXIX-XLVI.

Procès-verbal de ce qui s'est passé au lit de justice tenu par le roi à Versailles, le mardi douze mars 1776. Paris: Imprimerie Royale, 1776.

ROBERTSON, William. The History of the reign of the Emperor Charles V (1769); edición: Londres: Strahan, 1802.

Silhouette, Étienne. Voyages de France, d'Espagne, de Portugal et d'Italie. Paris: Merlin, 1770 .

[SOlER Y FANECA, Juan]. Dicertación del antiguo edificio de la Casa Lonja y noticia de lo que ha ocurrido durante la construcción de las obras... En Moliné y Brasés, Ernest. Les 
Costums marítimes de Barcelona universalment conegudes per Llibre del Consolat de

Mar. Barcelona: Henrich, 1914, pp. 360-366.

VOlTAIRE. Oeuvres. Ámsterdam: É. Ledet et cie, 1739, vol. IV.

Walpole, Horace. Anecdotes of Painting in England. Londres: Dodsley, 1782, 3. ${ }^{a}$ ed.

\section{Estudios modernos}

Berbel Rodríguez, José Juan. «Introducción». En CAPMANY y MONTPALAU, Antonio de. Filosofía de la elocuencia (1777). Almería: Universidad de Almería, 2002, pp. 7-25.

DESDEvises Du DÉZerT, Georges. L'Espagne de l'Ancien Régime. Paris: Société de l'imprimerie et de librairie, 1904.

Díez, Fernando. "El gremialismo de Antonio de Capmany (1742-1813). La idea del trabajo de un conservador ingenuo". Historia y política. Ideas, procesos y movimientos sociales. Madrid, 5, 2001, pp. 171-206.

ÉTIENVRE, Françoise. «Introducción biográfica y crítica». En CAPMANY, Antonio de. Centinela contra franceses. Londres: Tamesis Books, 1988, pp. 13-72.

ÉTIENVRE, Françoise. Rhétorique et patrie dans l'Espagne des Lumières. L'oeuvre linguistique d'Antonio de Capmany (1742-1813). Paris: Honoré Champion, 2001.

ÉTIENVRE, Françoise. «Nación y constitución en Antonio de Capmany». En CANTERLA, Cinta (coord.). Nación y constitución: de la Ilustración al liberalismo. Sevilla: Junta de Andalucía, 2006, pp. 265-275.

FERnÁNDEZ DE la Cigoña, Francisco José y CANTERo, Estanislao. Antonio de Capmany (17421813). Pensamiento, obra histórica, política y jurídica. Madrid: Fundación Francisco Elías de Tejada y Erasmo Percopo, 1993.

GRAu i FERnández, Ramon. Antoni de Capmany i la renovació de l'bistoricisme polític català. Barcelona: Ajuntament de Barcelona, 2006, Quaderns del Seminari d'Història de Barcelona, 8.

GRAU I FERNÁNDEZ, Ramon. "Inventores de la modernidad: Capmany y Cerdà en Barcelona». En Grau, Ramon y MuÑoz, Josep M. Cataluña, una historia europea. Barcelona: Generalitat de Catalunya, 2006, pp. 86-95.

GRAU I FERNÁNDEZ, Ramon. "Pierre Vilar, Antoni de Capmany i la "gimnàstica mental”». En El (re)descobriment de l'Edat Moderna. Estudis en homenatge a Eulàlia Duran. Barcelona: Publicacions de l'Abadia de Montserrat, 2007, pp. 199-217.

GRAU I FERNÁNDEZ, Ramon. "Indústria urbana o indústria dispersa? El rerefons polític d'una polèmica, 1773-1778». En SÁNCHEZ, Àlex (coord.). La indústria de les indianes a Barcelona, 1730-1850. Barcelona: Ajuntament de Barcelona, 2011, Barcelona Quaderns d'Història, 17, pp. 149-195.

GRAU i FERNÁNDEZ, Ramon. "Antoni de Capmany i la teoria marítima de Barcelona». En Grau, Ramon (coord.). Barcelona i el mar. Homenatge a Antoni de Capmany, 17421813. Barcelona: Ajuntament de Barcelon, 2014, Barcelona Quaderns d'Història, 21, pp. 19-42.

GraU, Ramon y LóPez, Marina. "Origen de la revaloració del gòtic a Barcelona: Capmany, 1792». En CubelEs, Albert y Grau, Ramon (coords.). El procés urbà i la identitat gòtica de Barcelona. Barcelona: Ajuntament de Barcelona, 2003, Barcelona Quaderns d'Història, 9, pp. 143-177. 
ANTONIO DE CAPMANY Y LA CIUDAD DE BARCELONA: EL VALOR DE LO EMPÍRICO...

JuRETSChKe, Hans. "La contestación de Capmany a Cadalso y su discurso de ingreso en la Academia de la Historia». Revista de la Universidad de Madrid, 1969, XVIII, 69, pp. 203-221.

LlucH, Ernest. El pensament econòmic a Catalunya (1760-1840). Barcelona: Edicions 62, 1973.

MaríAs, Julián. La España posible en tiempo de Carlos III. Madrid: Sociedad de Estudios y Publicaciones, 1963.

MeINECKE, Friedrich. Die Entstehung des Historismus. Berlín, 1936 (versión castellana: El historicismo y su génesis. México: Fondo de Cultura Económica, 1943).

Touchard, Jean. Historia de las ideas politicas. Madrid: Tecnos, 1964.

VILAR, Pierre. Assaigs sobre la Catalunya del segle XVIII. Barcelona: Curial, 1973, pp. 91-171. 